\title{
Representaciones del tercer mundo
}

La territorialización de la Terra Australis en la cartografia del siglo XVI

Representações do terceiro mundo: A territorialização da Terra Australis na cartografia do século XVI

Representations of the third world: The territorialization of Terra Australis in the $16^{\text {th }}$ century cartography

Representations du tiers-monde: La territorialisation de la Terra Australis dans la cartographie du XVIème siecle

\section{Luis Ignacio de Lasa and María Teresa Luiz}

\section{(2) OpenEdition}

\section{Journals}

Electronic version

URL: https://journals.openedition.org/terrabrasilis/5346

DOI: $10.4000 /$ terrabrasilis.5346

ISSN: 2316-7793

Publisher

Rede Brasileira de História da Geografia e Geografia Histórica

Electronic reference

Luis Ignacio de Lasa and María Teresa Luiz, "Representaciones del tercer mundo", Terra Brasilis [Online], 12 | 2019, Online since 29 December 2019, connection on 05 December 2022. URL: http:// journals.openedition.org/terrabrasilis/5346 ; DOI: https://doi.org/10.4000/terrabrasilis.5346

This text was automatically generated on 5 December 2022

All rights reserved 


\title{
Representaciones del tercer mundo
}

\author{
La territorialización de la Terra Australis en la cartografia del siglo XVI \\ Representações do terceiro mundo: A territorialização da Terra Australis na \\ cartografia do século XVI \\ Representations of the third world: The territorialization of Terra Australis in \\ the $16^{\text {th }}$ century cartography \\ Representations du tiers-monde : La territorialisation de la Terra Australis \\ dans la cartographie du XVIème siecle
}

Luis Ignacio de Lasa and María Teresa Luiz

\section{Introducción}

La cartografía producida desde el inicio de la expansión atlántica de los reinos ibéricos y durante el siglo XVI constituye un valioso repositorio de indicios para acceder a los modos en que el espacio fue percibido, interpretado y conceptualizado a partir de los nuevos datos empíricos y de un conjunto de referencias geográficas y cosmográficas, simbólicas e imaginarias de larga duración en los sistemas de pensamiento europeos. Los mapas del Renacimiento pueden considerarse síntesis de diferentes tipos de conocimiento que se expresan en ideas sobre el espacio abstracto, imaginado y vivido. ${ }^{1}$ En un primer momento, el espacio inasequible y aún inexplorado es comprendido mediante conceptos - derivados de la observación astronómica, el cálculo matemático y la demostración geométrica - que posibilitan una prefiguración de tierras y océanos; al mismo tiempo, una rica herencia de relatos históricos y literarios, mitos y creencias permite dotar de contenido a las formas posibles. Progresivamente, el espacio apropiado a través del pensamiento especulativo y la imaginación creativa es puesto en tensión por la observación y la experiencia de los viajes, desarrollándose nuevas relaciones con lo conocido y lo desconocido, categorías estas que, como señala Lois (2010: 4), no pueden pensarse en términos dicotómicos, sino reconociendo su mutua implicación en la construcción de explicaciones verosímiles. Desde las proposiciones teóricas y perspectivas metodológicas que ofrecen los estudios de cartografía histórica 
desarrollados en los últimos años, proponemos indagar sobre los modos en que se expresan estas relaciones en el discurso cartográfico desplegado en planisferios, globos y mapas regionales construidos en Europa durante el siglo XVI. ${ }^{2}$

En esta aproximación consideramos los factores que durante el inicio del proceso de descubrimiento y exploración de Patagonia y Tierra del Fuego condicionaron las representaciones del espacio $^{3}$ y la producción cartográfica: a) el contexto epistemológico del Renacimiento y las representaciones del orbis terrarum que retoman las concepciones geográficas clásicas y los contenidos del imaginario antiguo y medieval; b) las formas de producción y organización del conocimiento geográfico del hemisferio sur que intentan compatibilizar la información resultante de la exploración con los marcos conceptuales vigentes; ${ }^{4} \mathrm{c}$ ) los intereses políticos y económicos que dinamizan las primeras etapas de la mundialización ${ }^{5}$ y la necesidad de contar con una visión completa de la superficie terrestre para el diseño de estrategias imperiales globales.

El examen de los registros cartográfico, icónico y verbal integrados en la trama discursiva de los mapas elaborados durante el siglo XVI busca iluminar el inicio del proceso de ecumenización del hemisferio sur ${ }^{6} \mathrm{y}$ la construcción de una imagen territorial ${ }^{7}$ del extremo meridional de América, identificando cambios y permanencias en las representaciones del espacio, atendiendo especialmente a la configuración geográfica de las tierras y los mares australes y las valoraciones sobre la naturaleza territorial desde las concepciones y los sistemas de referencia que daban sentido a las nuevas evidencias y los proyectos de dominio.

4 Considerando que la imagen del extremo sur continental no puede desvincularse de la idea geográfica que fue formándose de América como un Nuevo Mundo y de la presunción de la existencia de otros mundos (Lois, 2010), mostraremos que su construcción fue condicionada tanto por las expectativas científicas, políticas y económicas respecto a la posibilidad de un ecumene austral como por las líneas de avance en el conocimiento del resto del hemisferio sur. Examinamos la incidencia de la hipótesis de la existencia de un continente meridional en la interpretación de la entidad de las tierras magallánicas como también su gravitación en el diseño imperial de España y en los planes de expansión de otros Estados europeos.

5 Analizamos asimismo el papel que jugó la producción cartográfica, condición y resultado de la labor exploratoria y de la primera organización jurisdiccional, en el proceso de territorialización del extremo austral del continente y de las tierras incógnitas adyacentes. ${ }^{8}$ Asumiendo que las territorialidades coloniales constituyen formas de apropiación material y simbólica del territorio, indagamos sobre los modos específicos de valorización, gestión y significación del espacio austral desde los intereses, necesidades y propósitos de los europeos. Interesa mostrar la participación de los mapas en la construcción de identidades territoriales, visualizando cómo el discurso cartográfico, al recrear elementos de diferenciación y calificación del espacio, contribuye a la conformación de una imagen territorial de Patagonia y Tierra del Fuego como frontera, confín del mundo conocido y pasaje a otro mundo posible.

6 La metodología construida en el diálogo con la teoría y las fuentes cartográficas comprende una aproximación a la dimensión cultural, política, institucional e ideológica de los mapas, la identificación de los códigos del lenguaje cartográfico ${ }^{9}$ y el análisis de las relaciones entre los registros cartográfico, iconográfico y verbal. ${ }^{10}$ Sirviéndonos de otras fuentes documentales -crónicas, historias generales, relaciones 
de viajes, cosmografías, Reales Cédulas, informes y otros documentos de la administración colonial - la lectura se organiza desde las hipótesis que atienden a las formas de organización del conocimiento geográfico y los factores que condicionaron las representaciones del espacio austral.

\section{La posibilidad de un ecumene austral}

7 Los intelectuales del Renacimiento se sirven del conocimiento grecolatino y árabe en el debate sobre la forma y extensión del ecumene y la distribución de tierras y aguas en la superficie de la esfera terrestre. La discusión activada por la revalorización de las fuentes antiguas y los descubrimientos geográficos modernos fue potenciada por la política atlántica de los reinos ibéricos interesados en ampliar el ámbito y frecuencia de sus navegaciones, condición para el establecimiento de rutas comerciales y la ampliación de sus dominios ultramarinos. ${ }^{11}$

8 A principios del XVI, al tiempo que se confirmaba la viabilidad de la conexión regular con la India circunnavegando África, continuaba la búsqueda de una comunicación con el Extremo Oriente a través del Atlántico. Desde este propósito, el avance exploratorio hacia el sudoeste permitió confirmar la entidad geográfica del Nuevo Mundo como continente o cuarta parte y la existencia de otras tierras australes que pronto serán interpretadas desde las concepciones geográficas vigentes como una quinta parte (Lois, 2008b).

9 La posibilidad de la existencia de un gran continente en el hemisferio sur constituyó una de las cuestiones que estimularon la especulación cosmográfica y el pensamiento imaginativo en la discusión sobre la imagen del mundo. La hipótesis habría encontrado fundamento en las fuentes clásicas, particularmente en la obra de Ptolomeo (siglo II d.c.), cuyo mapamundi representaba una masa de tierra que unía África con Asia cerrando el océano Indico a los $15^{\circ} \mathrm{LS} .{ }^{12}$ Desde la noción de la esfericidad de la tierra sostenida por los griegos desde el siglo IV a.C., esta masa terrestre se consideraba necesaria para equilibrar la que en el hemisferio septentrional comprendía las tres partes del ecumene, Asia, África y Europa ${ }^{13}$ Asimismo, la teoría de las zonas climáticas ${ }^{14}$ permitía suponer un ecumene simétricamente opuesto y especular al orbe conocido y habitado en la zona templada del hemisferio austral. Tras comprobarse la habitabilidad de la zona tórrida y la posibilidad de extender las rutas de navegación atravesando los trópicos, ${ }^{15}$ la idea de encontrar nuevas tierras habitadas al sur fue ganando fuerza, imponiéndose a la creencia medieval de un continente antípodas inaccesible y poblado con monstruos y seres fabulosos. ${ }^{16}$

10 El debate sobre la existencia de un vasto continente austral durante el siglo XVI expresa la tensión entre el conocimiento teórico, especulativo o imaginativo que se enraíza en la tradición clásica y el conocimiento empírico que va adquiriendo mayor fuerza a partir de la ampliación de la información geográfica. Los globos de fines de siglo XV Martín Behaim (1492) y Laon (1493) - y sobre todo los mapamundis de principios del XVI - Juan de la Cosa (1500), Cantino (1502) y Caverio (1505) - ponen en juego conceptos cosmográficos similares $\mathrm{y}$, al mismo tiempo, inician una radical transformación cartográfica, integrando de diferentes formas los descubrimientos atlánticos al marco consagrado y mostrando una "geografía en expansión" (Day, 1988; Lois, 2008a). 
11 Las noticias del tercer viaje de Américo Vespucio (1501-1502) dieron un giro inesperado a las exploraciones y sobre todo al debate sobre la naturaleza de las islas o tierras descubiertas durante la década anterior. En la carta donde expone los descubrimientos realizados durante la expedición dirigida por Gonzalo Coelho, encomendada por Juan II para la búsqueda de un paso marítimo por el sur, Vespucio presenta dos ideas que alteran el marco conceptual vigente; ${ }^{17}$ por un lado, sostiene que las tierras transatlánticas no eran parte de Asia como lo postulaba la tesis de Colón sino que formaban un nuevo mundo - es decir, un continente separado del orbe conocido - y, por otro, afirma la habitabilidad de las regiones equinocciales, declarando haber visto en su navegación austral a los antípodas, que describe como caníbales e idólatras. ${ }^{18}$

La concepción de Vespucio tuvo una amplia difusión y fue expresada cartográficamente por el cosmógrafo Martin Waldseemüller (c.1470-1518) en el mapamundi que acompañó la obra Cosmographiae introductio, publicada en Estrasburgo en 1507 (Figura 1). El mapa representa las tres partes o continentes del ecumene clásico como una única masa terrestre y las nuevas tierras descubiertas en el Atlántico como islas. La mayor de estas islas (actual América del Sur) es identificada como Nuevo Mundo, cuarta parte o América en honor a quien considera su descubridor, Américo Vespucio. El contorno sudamericano se delinea hasta los $42^{\circ}$ LS aproximadamente, señalando el punto más austral alcanzado por Vespucio con una bandera portuguesa. ${ }^{19} \mathrm{Si}$ bien se incluyen otras islas australes, algunas cortadas por el borde del mapa al igual que el extremo sur americano, ${ }^{20}$ éstas serían un resabio de la Terra Incógnita de Ptolomeo, aunque en la Cosmografía afirma, siguiendo a Vespucio, que las antípodas existen. ${ }^{21}$ Esta referencia sobre la existencia de tierras habitadas en la zona templada austral proporcionada por autoridades del saber cosmográfico de la época podría considerarse un primer antecedente en el proceso de ecumenización del hemisferio sur y en la construcción de la representación territorial de las tierras australes. 
Figura 1. Martin Waldseemüler, Universalis cosmographia secundum Ptholomaie traditionem et Americi Vespucii alioru[m]que lustratione, St. Dié, 1507

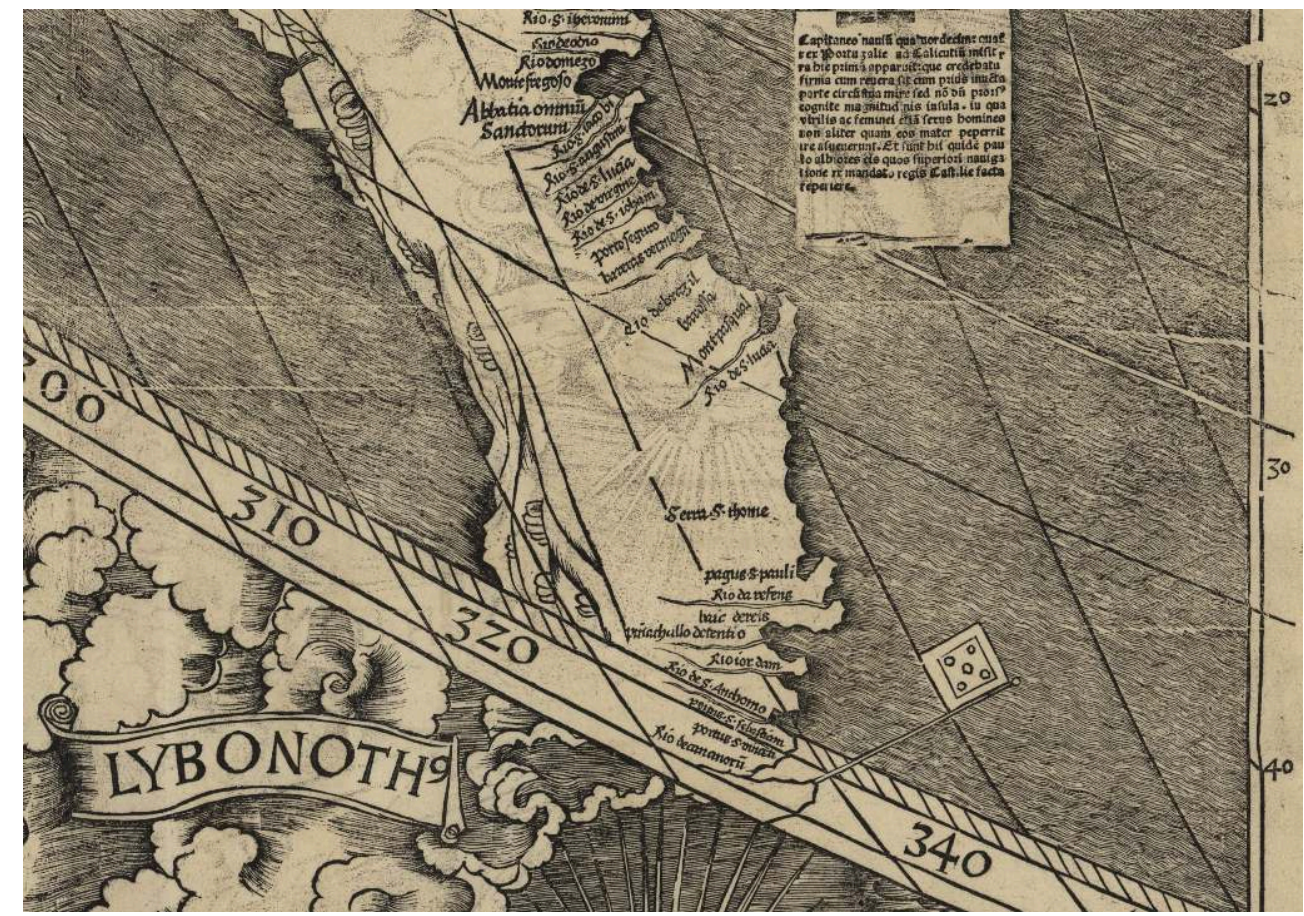

Fonte: Library of Congress Geography. Washington, D.C. Disponible en: https://www.loc.gov/item/ 2003626426/

El mapamundi de Francesco Roselli (c.1508), confeccionado con la proyección oval que permite una imagen de la totalidad de la esfera terrestre, ofrece una representación completa del hemisferio austral en la que se reconocen distintas fuentes: el contorno del Nuevo Mundo con una península hasta los $50^{\circ}$ LS se basa en Vespucio, África se extiende hasta los $35^{\circ}$ LS de acuerdo a las exploraciones portuguesas, la configuración del sur de Asia y las islas adyacentes sigue a Ptolomeo y el planteo de una gran isla austral - Antarticus - también podría derivar de fuentes clásicas. Desde la perspectiva de la construcción territorial interesa destacar la representación de esta masa terrestre por debajo de los $50^{\circ} \mathrm{LS}$, en cuya costa norte, delineada por encima del círculo antártico, se ubican cinco iconos de ciudades que permiten suponer la habitabilidad en la zona templada austral. ${ }^{22}$

El globo construido en 1515 por el cosmógrafo de Johann Schöner (1477-1547) y el mapa del hemisferio austral de Henricus Glareanus de 1513, tomando como fuente la Cosmographie de Waldseemüller, también representan un Nuevo Mundo insular que se extiende hasta aproximadamente los $50^{\circ}$ LS. Mientras el segundo propone un hemisferio sur oceánico, Schöner plantea la existencia de tierras australes, representando un continente con forma anular que se desarrolla longitudinalmente dentro de la zona templada, separado del Nuevo Mundo por un estrecho. ${ }^{23}$ Esta representación de un gran continente centrado en el Polo Sur anticipa una configuración posible al proponer la relación entre la masa terrestre austral y el extremo sur americano, configuración que el cartógrafo mantiene en el globo de 1520 con alguna variación de topónimos (Figura 2). 
Figura 2. 1520. Johannes Schöner, Globus

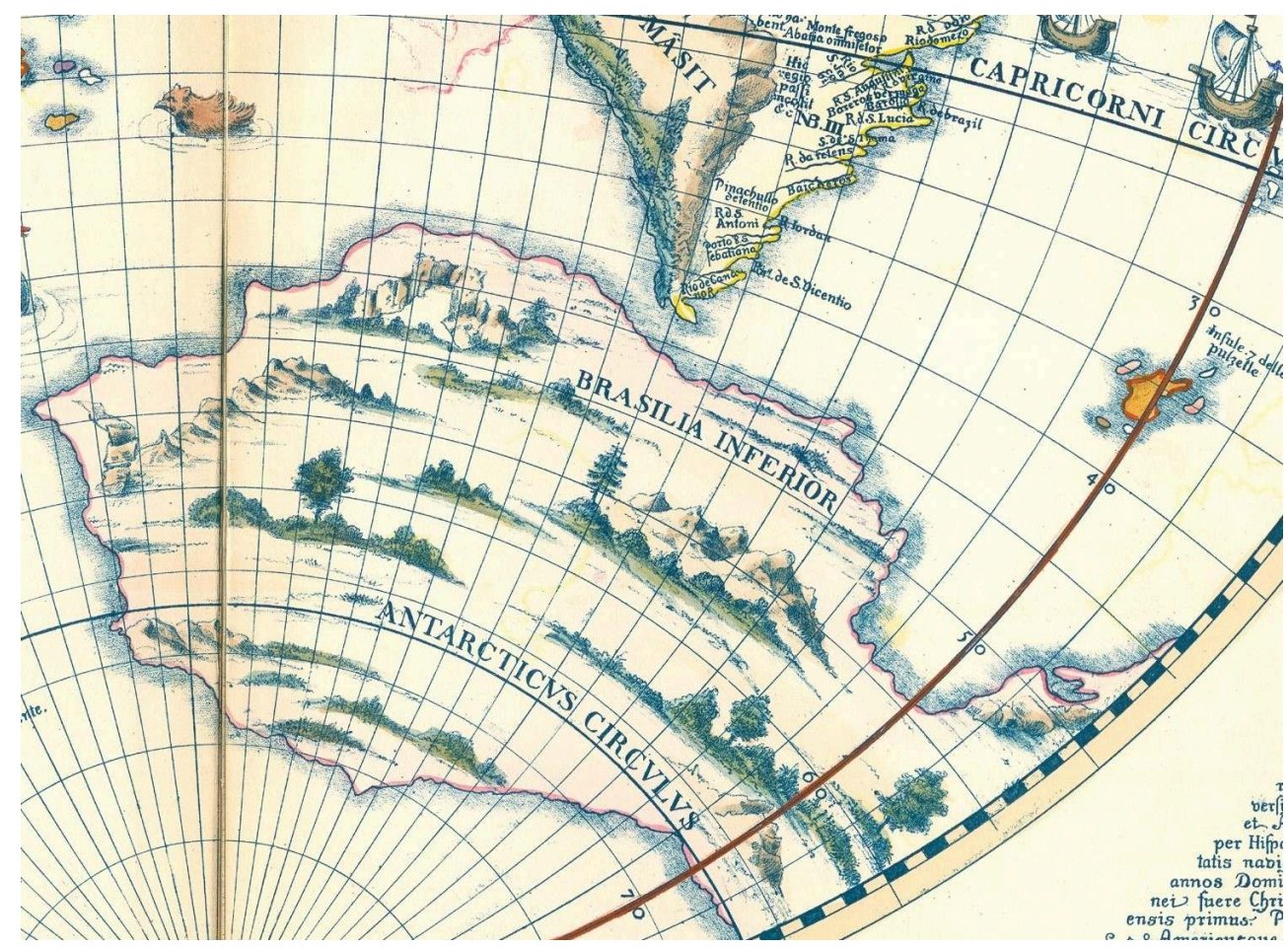

Fonte: National Library of Finland - Doria. Disponible en: http://www.doria.fi/handle/10024/93741

Otra fuente de interés desde la perspectiva de nuestro análisis es la Carta del Océano Atlántico de Piri Reis de 1513, único fragmento conservado de un mapamundi elaborado con fuentes europeas y árabes que representa las costas atlánticas de África, la península ibérica y el Nuevo Mundo. Más allá de las interpretaciones propuestas sobre la configuración de Sudamérica y la posible temprana representación de un continente austral, interesa señalar el valor del mapa como fuente de indicios para acceder al imaginario geográfico del hemisferio sur a principios del siglo XVI. Los elementos iconográficos - seres humanos salvajes y razas monstruosas, animales míticos, especias y oro - dan cuenta de la integración de referencias heredadas del universo simbólico medieval y de nuevos datos geográficos en las primeras representaciones cartográficas del espacio austral (McIntosh, 2000; Guedes, 2009).

\section{Tierra del Fuego: primera evidencia e inicio del debate territorializante}

Durante la segunda década del siglo XVI, mientras los españoles intensificaban la búsqueda de un paso hacia Oriente por el sur del Nuevo Mundo, alentados por el descubrimiento del Mar del Sur tras el cruce del istmo centroamericano por Vasco Núñez de Balboa, los portugueses lograban acceder a las principales islas productoras de especias - las Molucas - vía el Cabo de Buena Esperanza, sin abandonar la posibilidad de encontrar una ruta alternativa más corta y directa navegando hacia el oeste.

Desde el Río de la Plata, primer ámbito de las exploraciones promovidas por ambas Coronas ${ }^{24}$ la expedición de Hernando de Magallanes costeó la tierra firme adelante de lo que estaba sabido y descubierto ${ }^{25}$ y efectuó el primer reconocimiento de las costas 
patagónicas durante los últimos meses de 1520. El plan para acceder a las Molucas ${ }^{26}$ contemplaba seguir la costa del Nuevo Mundo hacia la parte austral, hasta ver si tenía cabo y fin aquella tierra firme, o hasta que hallase el gran pasaje por donde se pudiese navegar $y$ pasar al otro mar del sur. ${ }^{27}$ En caso de no hallarse paso o estrecho, por extenderse la tierra firme conocida de polo a polo, ${ }^{28}$ costeando toda la tierra iría a salir al cabo que corresponde al de Buena Esperanza y descubriría nuevas y muchas tierras y camino para la Especiería, como prometía. ${ }^{29}$

18 La navegación de la flota de Magallanes hacia el interior del brazo de mar hallado a los $52^{\circ}$ LS permitió confirmar que el paso interoceánico era un estrecho entre la tierra firme que venían costeando y otra tierra desconocida ${ }^{30}$ que creyeron ser isla y conjeturaron estaba habitada porque una noche vieron gran multitud de fuegos en la tierra que estaba a la mano siniestra del estrecho hacia el austro. ${ }^{31}$

El descubrimiento de un nuevo océano y la primera circunnavegación del mundo aportaron nuevos datos a la discusión sobre el diámetro de la esfera terrestre y la extensión del orbis terrarum, necesarios además para avanzar en la determinación del antimeridiano de Tordesillas que delimitaba las jurisdicciones ibéricas en Oriente pues la información geográfica era manipulada en función de los intereses de cada parte: los portugueses acortaban la distancia entre Guinea y Calcuta y los españoles disminuían el ancho del Pacífico y ubicaban las Molucas dentro de su zona de influencia (MartínMerás, 1993; Padrón, 2010). Asimismo, el hallazgo de nuevas tierras australes supuestamente habitadas abrió nuevos interrogantes que imponían revisar los presupuestos desde los que se pensaba la conformación geográfica del hemisferio sur y la relación entre ecumene y globo terrestre.

El diseño del plan de la expedición de Magallanes, resultado de la síntesis del conocimiento empírico y del especulativo, ${ }^{32}$ muestra la vigencia de distintas concepciones espaciales vigentes. Mientras la búsqueda de un paso oceánico al término de la tierra firme entre los $35^{\circ}$ y los $50^{\circ}$ LS resultaba una alternativa desde los presupuestos de un Nuevo Mundo insular y de una configuración marítima del hemisferio sur, las hipótesis del estrecho y de la continuidad de las tierras hasta el Polo suponían aceptar la posibilidad de una o varias masas de tierra en la zona templada y frígida austral.

21 Si bien la existencia de una o más islas comparables al orbis terrarum en otros hemisferios no era la hipótesis más aceptada a fines del siglo XVI, los nuevos descubrimientos atlánticos permitían sostener esta distribución. La representación de la isla de América independiente de la Isla de Tierra del mundo conocido e integrada al orbe como "cuarta parte", tal como lo expresa el mapamundi de Waldseemüller (O'Gorman, 1995), habilitaba pensar la existencia de otras tierras o islas de la misma naturaleza en el hemisferio meridional. La posibilidad encontraba además un buen fundamento en las nociones clásicas de equilibro y simetría, retomadas en las obras de eruditos medievales de gran influencia, como Bacon y d'Ailly. Desde esta concepción, y considerándose que las tierras emergidas formaban un todo continuo que encerraba grandes cuerpos de agua, los cartógrafos tendieron a "poblar los espacios antes reservados al mar con cada vez mayores extensiones de hipotéticas tierras" (O'Gorman, 1995: 144) que en el hemisferio sur cerraban los océanos y equilibraban las masas terrestres del hemisferio norte.

De este modo, si durante las dos primeras décadas del siglo XVI algunos planisferios y globos representan tierras supuestas próximas al Polo Sur, en las décadas siguientes los 
mapas plantean su existencia atribuyéndoles distintas formas - isla, archipiélago o continente - y describen su naturaleza territorial con recursos cartográficos que, como precisaremos más adelante, expresan la suposición de la habitabilidad de la zona templada austral.

La hipótesis de un continente meridional encontró un primer anclaje empírico en las tierras que se extendían al sur del estrecho de Magallanes y, más allá de los datos que pudieron poner en duda su estatus geográfico, como la referencia aportada por Francisco de Hoces en 1526 sobre "el acabamiento de la tierra", ${ }^{33}$ numerosos mapas de gran circulación en las décadas centrales del siglo XVI incluyen en él a Tierra del Fuego. La configuración continental de las tierras australes se expresa en representaciones que proponen distintas formas y dimensiones: a) una masa de tierra ininterrumpida hasta el Polo (Thorne 1527, Fineus 1531, Schöner 1523, Mercator 1538), b) un continente interrumpido alrededor de los $66^{\circ}$ LS o en cercanías de la zona frígida (globo Nancy 1535, Desceliers 1546, Vallard 1547, Agnese 1544), c) un continente anular (Schöner 1515 y 1520, Tramezzino 1554).

La escasa estabilidad de las propuestas explicativas en un momento de gran dinamismo de las exploraciones se evidencia en la producción de un mismo cartógrafo, Johann Schöner, que plantea la última alternativa en sus primeros globos de 1515 y 1520 pero luego la abandona, ya que en el mapa de 1523 representa un archipiélago de grandes islas y en el globo de 1533 un continente completo con el topónimo Terra Australis. Según Stevenson (1921), Schöner sería el iniciador de una nueva concepción sobre hemisferio sur, que incluye tierras en las cercanías del Polo y, atendiendo a las similitudes en la configuración, extensión y topónimos, señala que los globos anónimos Paris Gilt (1528), Nancy (1535) y Paris Wooden (1535), así como el mapamundi de Fineus (1531), podrían considerarse como parte de la escuela schöneriana.

Nova et Integra Universi Orbis Descriptio de Oronce Fineus (1494-1555) (Figura 3) es el primer mapa impreso que delinea el contorno de la tierra meridional del estrecho de Magallanes como parte de un continente que cubre el Polo sur (Martinic, 1999). La proyección polar de los hemisferios boreal y austral permite una clara visualización de la contigüidad entre el extremo sur del Nuevo Mundo y este gran continente en el que, según Sankey (2003), aparece por primera vez el topónimo Terra Australis, seguido de la inscripción recenter inventa sed nondum plene cognita y dos topónimos localizados en el hemisferio oriental, Brasielie Regio y Regio Patalis. 
Figura 3. 1531. Oronce Fine, Nova, et integra vniversi orbis descriptio

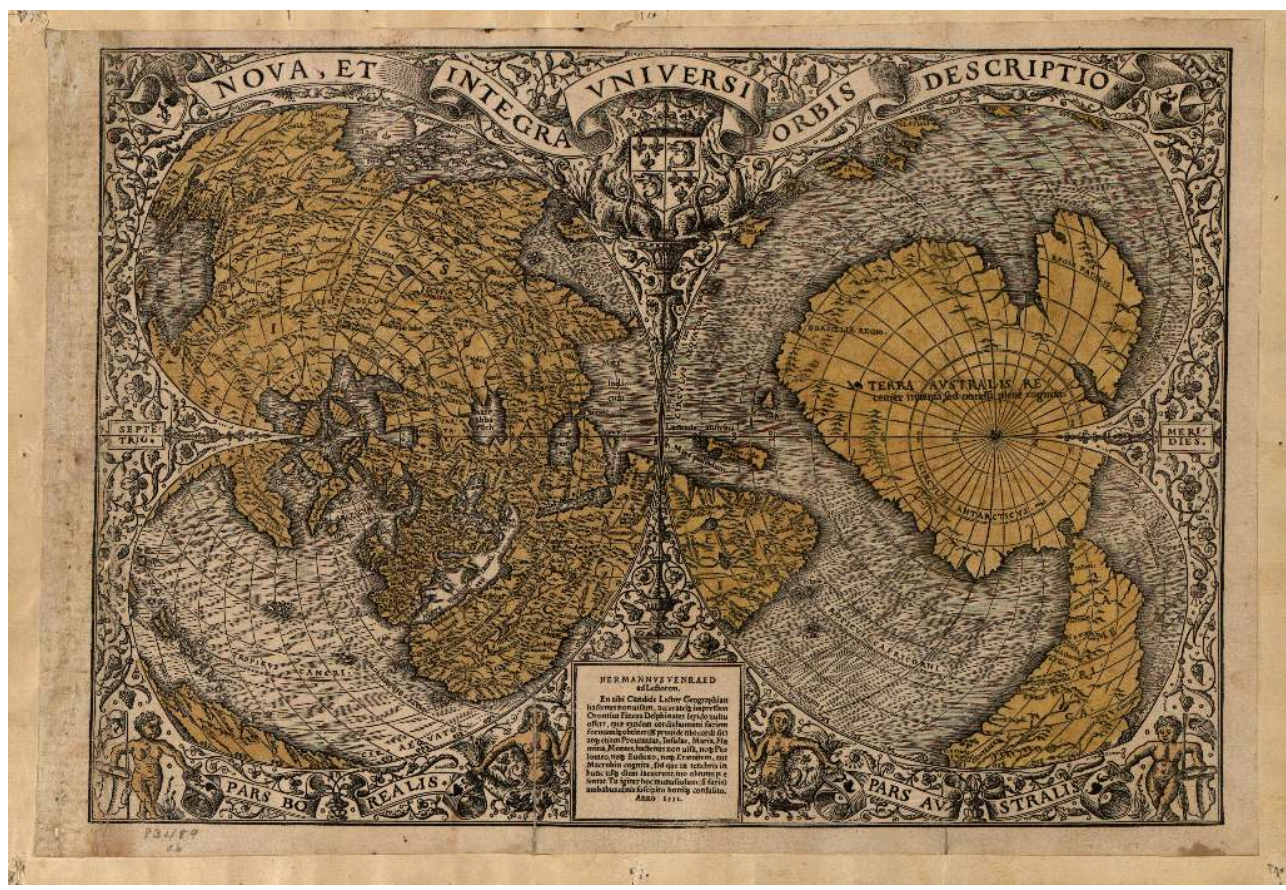

Fonte: Library of Congress. Geography and Map Division. Disponible en: http://hdl.loc.gov/loc.gmd/ g3200.ct001393

Gerard Mercator (1512-1594) completa el proceso de construcción de una nueva imagen cartográfica del mundo iniciado por Wadlseemüller y Schöner representando América como un Nuevo Mundo separado del Viejo Mundo por un estrecho en el Artico y de una masa terrestre meridional - denominada Quinta Pars - por el Estrecho de Magallanes. Optando por un modelo que privilegió la idea de equilibrio a la de simetría, Mercator argumenta la importancia de la distribución de los dos elementos aristotélicos que formaban el globo terrestre - tierra y agua - y busca equilibrarlos entre sí en los hemisferios norte y sur (Zuber, 2011). Desde esta concepción, basándose en fuentes clásicas y medievales y en la información sobre las costas conocidas de Tierra del Fuego y Nueva Guinea, dio forma al gran continente austral en su globo de $1541 \mathrm{y}$ en el mapamundi de 1569. La representación permite inferir una hipotetización sobre sus características territoriales: mientras la región magallánica no recibe un nombre propio y solo consigna tres topónimos sobre la ruta del estrecho, en las tierras tropicales al sur del Indico identifica dos regiones, Beach provincia aurifera y Maletur regnun, tomando como fuente a Marco Polo.

Junto a la hipótesis de la continentalidad de las tierras australes circularon otras interpretaciones que proponían una configuración insular con las variantes de isla, archipiélago o isla de tierra. ${ }^{34} \mathrm{El}$ cosmógrafo de la Casa de Contratación Alonso de Santa Cruz precisa en su Islario (c. 1545) que la tierra al sur del estrecho consta ser isla. Explicitando su crítica a Oroncio y otros fuera de España y siguiendo a autores ciertos y dignos de fe describe lo descubierto de esta isla desde cincuenta y tres grados hasta cincuenta y seis de acuerdo a la más reciente información de la expedición capitulada con Francisco de Camargo y dirigida por Francisco de la Rivera: quien más ha descubierto de esta parte o isla que al presente tratamos, es la armada del obispo de Plasencia que antes de entrar en el estrecho descubrió más cien leguas de costa viendo ser la tierra muy alta y de muchas montañas y habitadas porque les hicieron hacer muchos fuegos y pasado el estrecho a la 
parte a si mismo austral, descubrieron de costa más de sesenta leguas y dos islas muy grandes con un archipiélago de islas pequeñas. El autor deja, sin embargo, un margen de ambigüedad pues, aunque afirma que se trata de una isla, la mayor que hay en el mundo la cual es la más próxima tierra al polo antártica, en el mapa la representa extendiendo considerablemente el litoral oriental de Tierra del Fuego y consignando la referencia Tierra o isla del estrecho de Magallanes. Además, ni en este mapa ni en el mapamundi de 1542 - en el que también prolonga longitudinalmente la costa septentrional de Tierra del Fuego hacia el oeste, sugiriendo que se trataría de una isla de gran tamaño -, el diseño de la costa atlántica se ajusta a los datos proporcionados por la expedición armada por el Obispo de Plasencia (1539 y 1540), ${ }^{35}$ consignados en el Islario.

Las discusiones sobre la naturaleza geográfica de las tierras australes se expresan cartográficamente en la coexistencia de mapas que solo representan las tierras y costas conocidas, gran parte de ellos derivados de la cartografía oficial española ${ }^{36}$ y mapas que intentan resolver la representación del hemisferio austral con los datos empíricos disponibles de acuerdo con las premisas clásicas de armonía, simetría y equilibrio que ofrecían un marco orientador del diseño y una garantía de veracidad. En estos últimos, que marcan la tendencia dominante sobre todo durante la segunda mitad del siglo XVI, la territorialización del continente austral se expresa a través de diversas estrategias: a) la inscripción de topónimos que identifican lugares y regiones ${ }^{37}$ - nombres inspirados en fuentes antiguas y medievales (Mercator), derivados de las exploraciones modernas (Schöner) o de la fantasía del cartógrafo (Roselli 1508 y Vaticano 1534); b) la inclusión de leyendas que refieren alguna particularidad observada o imaginada del espacio y de sus habitantes o hacen alusión a recursos de interés (perlas, especies, oro); c) la representación de detalles topográficos y de ciudades antípodas; d) el trazado de los paralelos de referencia (trópicos y círculos polares) que indicaban las tierras habitables entre los $23^{\circ} 30^{\prime}$ y los $66^{\circ} 30^{\prime} \mathrm{LS}$. El uso regular de este último elemento permite advertir que la teoría de las zonas climáticas (Cattaneo, 2009), aunque algo desacreditada por las evidencias para los trópicos, continuaba ofreciendo un criterio para ordenar las hipótesis de habitabilidad en los espacios aún inexplorados.

Las leyendas e ilustraciones de algunos mapas ofrecen información sobre las visiones que juegan en la representación de las tierras halladas o supuestas del hemisferio sur. Mientras las noticias que circularon de los primeros viajes al Pacífico sur ${ }^{38}$ permitieron alimentar la creencia en un continente austral con recursos de interés comercial, la información sobre el extremo meridional del Nuevo Mundo y las tierras adyacentes resultaba menos alentadora.

31 La Carta Universal de Diego de Ribero de 1529, mapamundi manuscrito derivado del Padrón Real, contiene algunos elementos sobre los que se construirá la imagen de Patagonia como un territorio inhóspito, habitados por Otros y de incierta utilidad. La (des)valorización oficial del extremo meridional de América se funda en la descripción de la Tierra de Patagones de acuerdo con los testimonios de los integrantes de la expedición de Magallanes, en especial la relación de Pigafetta: la tierra es estéril y de ningún provecho y los indios son hombres de cuerpos grandes, casi gigantes (Figura 4). 
Figura 4. 1529. Diego Ribero, Carta universal

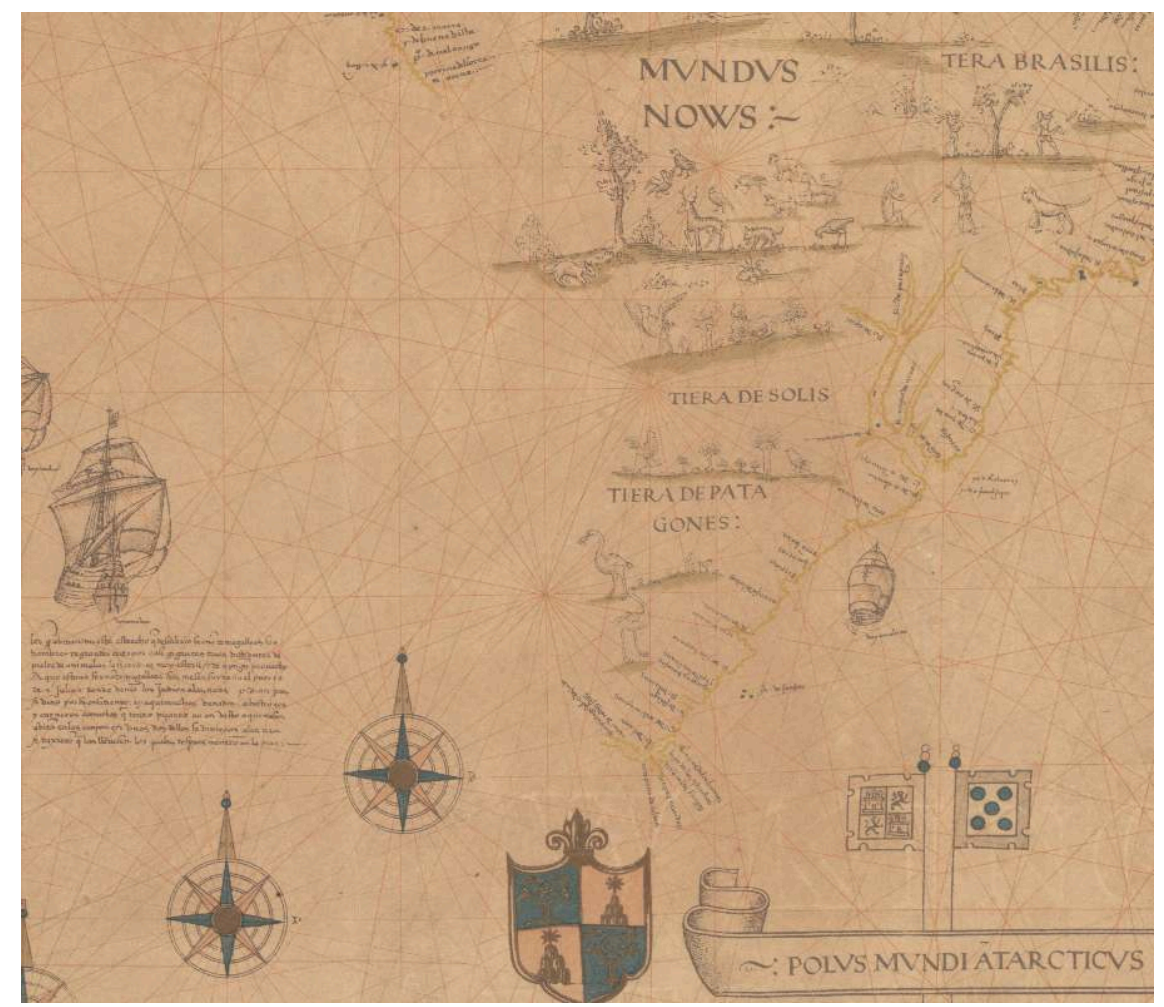

Fonte: National Library of Australia Digital Collections. Disponible en: http://nla.gov.au/nla.mapnk5631

En la representación de la Terra Australis de los mapamundis elaborados por los cartógrafos de Dieppe a partir de la década de 1540 también resulta significativa la diferencia entre la región magallánica y las tierras al sur de la Molucas; mientras Tierra del Fuego se presenta como un espacio vacío - desconocido, ignorado o sin valor- o como una tierra de salvajes en los confines del ecumene, Java la Grande, al sur de Sumatra, es descripta como un territorio rico y civilizado.

El atlas del piloto y cartógrafo francés Guillaume Le Testu (1509-1573), Cosmographie Universelle (1555) (Figura 5), confeccionado después de la expedición enviada a Brasil por Francisco I en 1551, en la que participa junto al cosmógrafo André Thevet, describe no solo una configuración posible de las tierras australes sino también un paisaje y una historia, aunque el autor advierte sobre el contenido "puramente imaginario" de las indicaciones y representaciones. Si bien el título presenta la obra como una cosmografía, su contenido la inscribiría en el dominio de las Geografías, en las que, como señala Lois (2008a: 78-79), "la descripción se convierte en el eje del texto y se distancia de los elementos astronómicos para acercarse a la historia, concibiéndose a ésta no sólo como el pasado sino como la actualización del conocimiento sobre la geografía del mundo". El atlas evidencia "la preocupación por la diversidad de los conjuntos morfológicos, hidrográficos y humanos" que, según esta autora, va definiendo una diferenciación entre cosmografía y geografía que toma cuerpo durante la segunda mitad del siglo XVI. Le Testu propone una circunnavegación imaginaria entre los $30^{\circ}$ y $50^{\circ} \mathrm{LS}$, representando un territorio construido desde las expectativas y la experiencia del Nuevo Mundo, propia y de otros navegantes. Inicia su itinerario en Java la Grande - un espacio privilegiado por los cartógrafos de Dieppe - y, tras recorrer 
el Mar de la India hacia el oeste, termina en Tierra del Fuego y el Estrecho de Magallanes, sector del continente austral que presenta, recreando elementos de la tradición medieval y del imaginario de América, como un mundo salvaje, atractivo y exótico. La apretada línea de topónimos en las costas conocidas refuerza la construcción territorial de un nuevo continente disponible para la conquista.

Figura 5. Guillaume Le Testu, Cosmographie Universelle, 1555

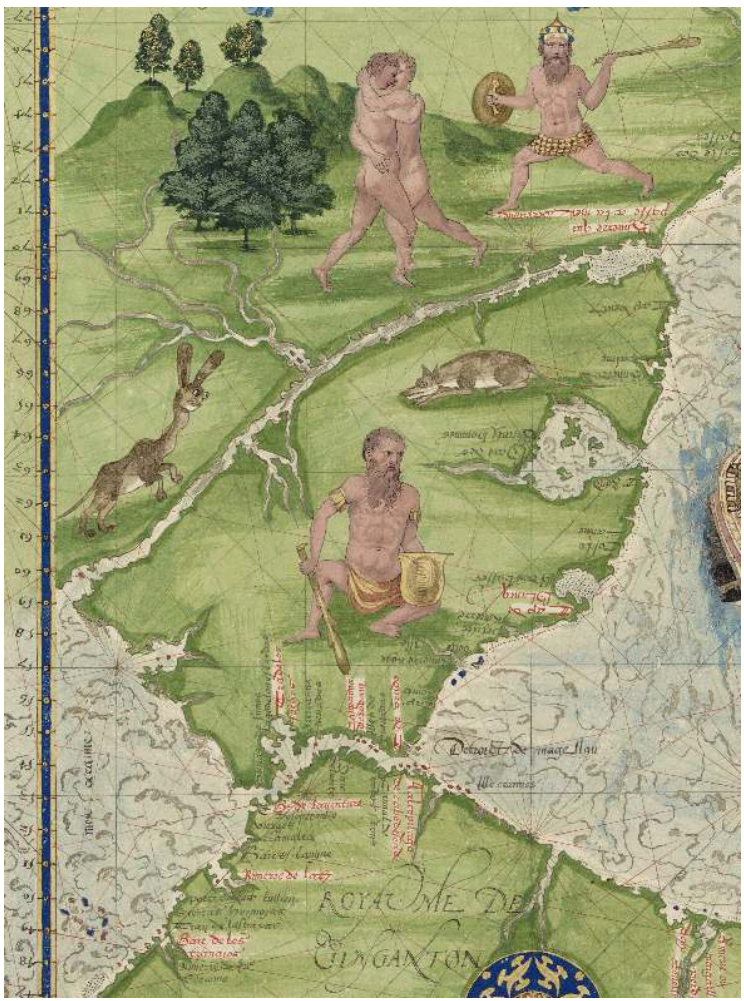

Fonte: Bibliotèque Nationale de France, Départament des Cartes et Plans. Disponible en: https:// gallica.bnf.fr/ark:/12148/btv1b8447838j/f88.item.r=.langES

\section{La incorporación formal y simbólica del extremo austral al territorio colonial}

El Estrecho de Magallanes se presentó como una ruta directa hacia la Especiería y una vía de comunicación alternativa entre la península y las posesiones castellanas del Pacífico, supuestamente menos complicada que la practicada por el Caribe a través del istmo. El principal objetivo de las expediciones que sucedieron a la de Magallanes - El Cano (1519-1522) ${ }^{39}$ fue entonces evaluar las condiciones de navegabilidad de la ruta pues el tránsito a través de un estrecho presentaba mayores riesgos que la navegación abierta.

Al mismo tiempo, el extremo sur era integrado al domino colonial en el primer macro ordenamiento jurisdiccional del espacio sudamericano derivado de la ampliación de la gobernación de Francisco Pizarro hasta los $14^{\circ}$ LS y de la creación de tres nuevas gobernaciones al sur de esta, según las capitulaciones firmadas en mayo de 1534 (Nocetti y Mir, 1997). La gobernación otorgada a Simón de Alcazaba, que comprendía 200 leguas entre los paralelos $36^{\circ}$ y $48^{\circ}$ con costas en ambos océanos, constituye la 
primera concesión territorial sobre Patagonia ${ }^{40}$ aunque la ocupación del puerto Los Leones ( $45^{\circ} \mathrm{LS}$ ) en marzo de 1535 fue abandonada tras los conflictos surgidos entre los integrantes de la tripulación. En otra capitulación celebrada en 1536 con el obispo de Plasencia, Gutierre de Vargas Carvajal, en representación de su hermano Francisco de Camargo, se formalizó una nueva jurisdicción sobre el extremo austral con el objetivo de concretar la conquista y población de las costas del Mar del Sur desde el término de las doscientas leguas otorgadas a Pedro de Mendoza hasta el Estrecho de Magallanes. La expedición dirigida por Francisco de la Rivera, tras la renuncia de Camargo, tampoco logró efectivizar una ocupación. ${ }^{41}$

El 24 de enero de 1539 se firmó otra capitulación con Pero Sancho de Hoz para descubrir por la costa del Mar del Sur el dicho Estrecho de Magallanes y la tierra que está de la otra parte de él, y en febrero del mismo año se le otorgó el cargo de Capitán General y el título de Gobernador con jurisdicción desde el límite meridional de la concedida a Camargo hasta las tierras al sur del estrecho. ${ }^{42} \mathrm{Si}$ bien la empresa no se llevó a cabo por la renuncia de su titular a los compromisos fijados en la capitulación ${ }^{43}$ estas proposiciones podrían considerarse como el primer antecedente jurídico en el proceso de territorialización del supuesto continente austral aunque la ambigüedad semántica de los textos evidencia el desconocimiento del estatus geográfico, pues de utilizan simultáneamente las categorías tierra, islas, isla e isla de tierra. ${ }^{44}$

Mientras los mapas elaborados en 1529 por el cosmógrafo de la Casa de Contratación Diego de Ribero podrían constituir la fuente cartográfica sobre la que se proyectaron las gobernaciones creadas entre 1534 y 1539, la Carta Universal de Alonso de Santa Cruz de 1542 (Figura 6) confirma el diseño jurisdiccional al ofrecer una imagen del espacio sudamericano en el inicio de la construcción del territorio colonial (Nocetti y Mir, 1997: 24). Este mapa consigna los nombres de las cuatro provincias emergentes de las primeras concesiones territoriales, concentra la mayor cantidad de topónimos costeros sobre el Atlántico y representa en el interior continental relieve, hidrografía, flora, fauna y algunos edificios. Las ilustraciones permiten establecer diferencias entre los distintos ámbitos y su escasez en la Provincia del Estrecho podría interpretarse en términos de desconocimiento, falta de ocupación efectiva o desinterés. 
Figura 6. Alonso de Santa Cruz Map of the world by the Spanish cosmographer Alonzo de Santa Cruz, 1542

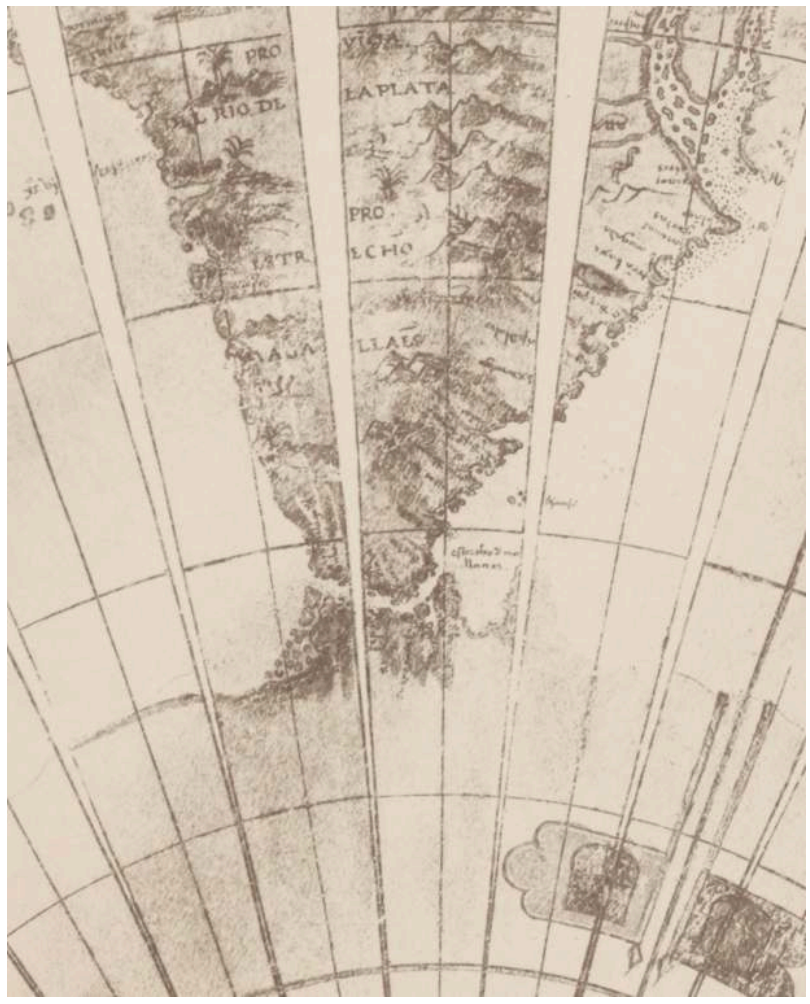

Fonte: National Library of Australia. Disponible en: https://nla.gov.au/nla.obj-231648462/view Gobernación de Chile cuando por Real Cédula del 29 de septiembre de 1554 se amplió la jurisdicción otorgada a Valdivia en $1548\left(27^{\circ}-41^{\circ}\right.$ LS) hasta el Estrecho de Magallanes. Su sucesor, Jerónimo de Alderete, recibió por Reales Cédulas firmadas el 29 de marzo de 1555 la misma jurisdicción territorial como también la facultad de descubrir, conquistar y poblar las tierras que están de la otra parte de dicho Estrecho (Martinic, 1981:8).

La cartografía oficial refuerza estas concesiones territoriales representando las tierras aún inexploradas dentro de la esfera de influencia castellana, es decir, no solo describe un territorio, sino que lo produce para actuar de acuerdo con ciertos intereses. La carta de América del cartógrafo de la Casa de Contratación Diego Gutiérrez, grabada en 1562 (Figura 7), evidencia la intencionalidad geopolítica al incluir la Tierra de Patagones, la Tierra de Magallanes (Tierra del Fuego) y la Regio Patalis (sobre el Pacífico) como ámbitos de posible expansión; incluso, la escena de un combate naval entre dos flotas en el Atlántico meridional podría enunciar la decisión de Felipe II de defender esta pretensión territorial (Kagan, 2005: 177). Junto a la referencia Gigantum regio, la representación de un encuentro entre dos gigantes patagones y un europeo identifica el territorio de conquista asociando las ideas sobre el espacio natural y salvaje al grado de humanidad de sus habitantes, recreando cartográficamente el relato de Pigafetta. 
Figura 7. 1562. Diego Gutiérrez, Americae sive qvartae orbis partis

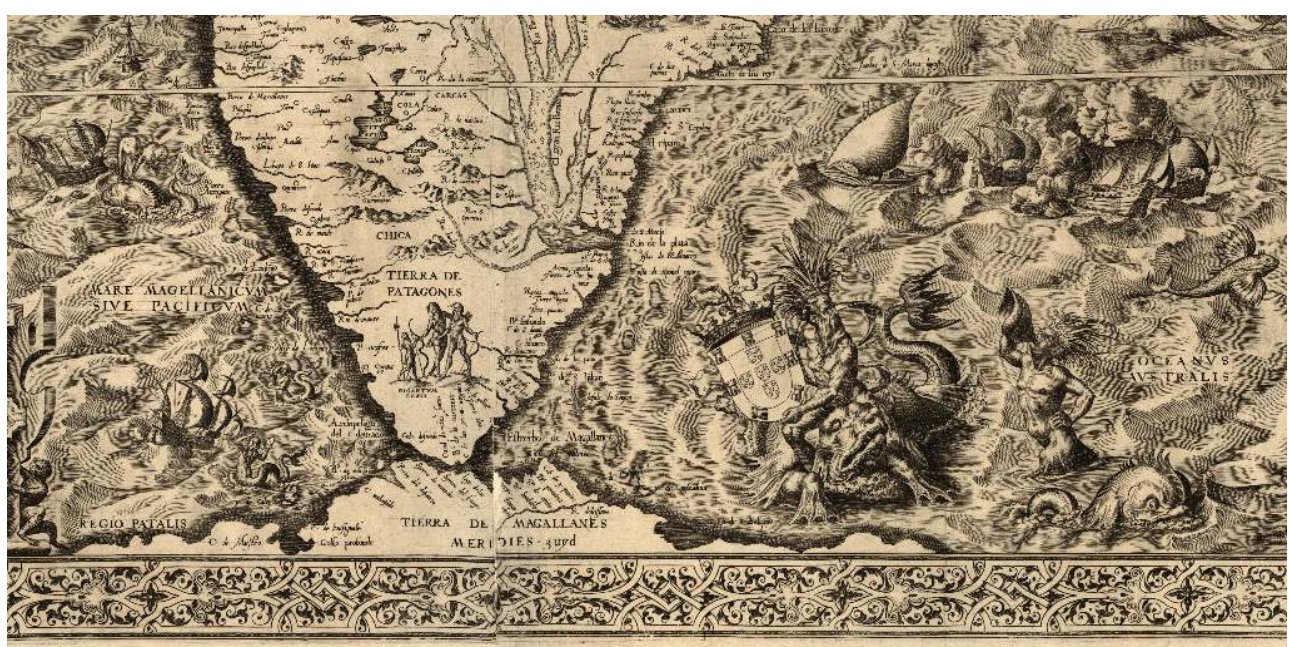

Fonte: Library of Congress. Geography and Map Division. Disponible en: http://hdl.loc.gov/loc.gmd/ g3290.ct000342

Pero más allá de las expectativas iniciales, la ruta del estrecho resultaba insegura por los vientos fuertes e inestables y la conformación misma del canal interoceánico, un verdadero laberinto de islas y canales, tal como lo demostraron los reconocimientos efectuados desde el Pacífico por orden de los gobernadores de Chile, el primero a cargo de Francisco de Ulloa entre 1553 y 1554 y el segundo más exhaustivo dirigido en 1558 por Juan Fernández Ladrillero. ${ }^{45}$ Por otro lado, la posibilidad de una comunicación regular entre Nueva España (Acapulco) y Filipinas (Manila), tras lograrse el buscado tornaviaje con la expedición de Legazpi-Urdaneta (1565), ofrecía una razón más para prescindir de la incierta navegación austral, por lo que el interés de la Corona se centró en el descubrimiento de islas y tierras en el Pacífico sur (Rodamilans Ramos, 2010: 106).

41 Pero el ingreso de Francis Drake al Pacífico por el estrecho y el asalto a los puertos de Valparaíso y El Callao en 1579 obligaron a España a dirigir nuevamente su atención hacia el extremo sur, y el desarrollo de un plan defensivo impuso algunos cambios jurisdiccionales, al nombrarse en 1581 a Pedro Sarmiento de Gamboa Gobernador y Capitán General de las poblaciones magallánicas (Martinic B., 1983). Los establecimientos fundados en 1584 en la margen norte del estrecho, Nombre de Jesús y Rey Don Felipe, alteraron brevemente el carácter nominal de la jurisdicción castellana sobre el espacio austral (Nocetti y Mir, 1997: 136-137).

Estas primeras concesiones territoriales, reforzadas por la cartografía oficial que identifica el territorio con denominaciones de carácter geográfico o administrativo, y la labor exploratoria, acompañada de actos de toma de posesión y nominación de lugares, constituyeron formas de apropiación intelectual y política de un espacio parcialmente explorado que revestía importancia geoestratégica para España con vistas a asegurar el control de la ruta austral y la defensa de las costas americanas del Pacífico.

\section{Diseños imperiales sobre la nueva imagen del mundo}

Desde la perspectiva de una estética geométrica, los cartógrafos del Renacimiento conciben entonces una imagen del orbe en la que la existencia de una gran masa terrestre austral resultaba necesaria para asegurar el equilibrio y la simetría de las 
formas entre los dos hemisferios. Esta concepción alcanza la máxima credibilidad con la obra de Abraham Ortelius (1527-1598), cuyo mapamundi fue modelo de representación del mundo durante medio siglo. El planisferio Typus Orbis Terrarum, publicado en el atlas Theatrum Orbis Terrarum (Amberes, 1570), contó con nueve ediciones hasta 1584 y otras dieciséis con ligeras modificaciones entre 1587 y1624 y el mapa titulado America Sive Novi Orbis Nova Descriptio tuvo veinticinco ediciones entre 1570 y 1624. (Martinic, 1999: 63-64) La clave del éxito radicó no solo en la valoración de los aspectos formales y científicos de la elaboración de mapas sino en la verosimilitud que otorga a la representación cartográfica de lo desconocido. La ampliación del mundo habitable más allá de los límites establecidos por la tradición posibilitó la construcción de un nuevo imaginario espacial que integra lo conocido y lo hipotético en un mismo plano de certidumbre (Besse, 2010; Sanchez, 2010) (Figura 8).

Figura 8. 1570. Abraham Ortelius, Typus Orbis Terrarum

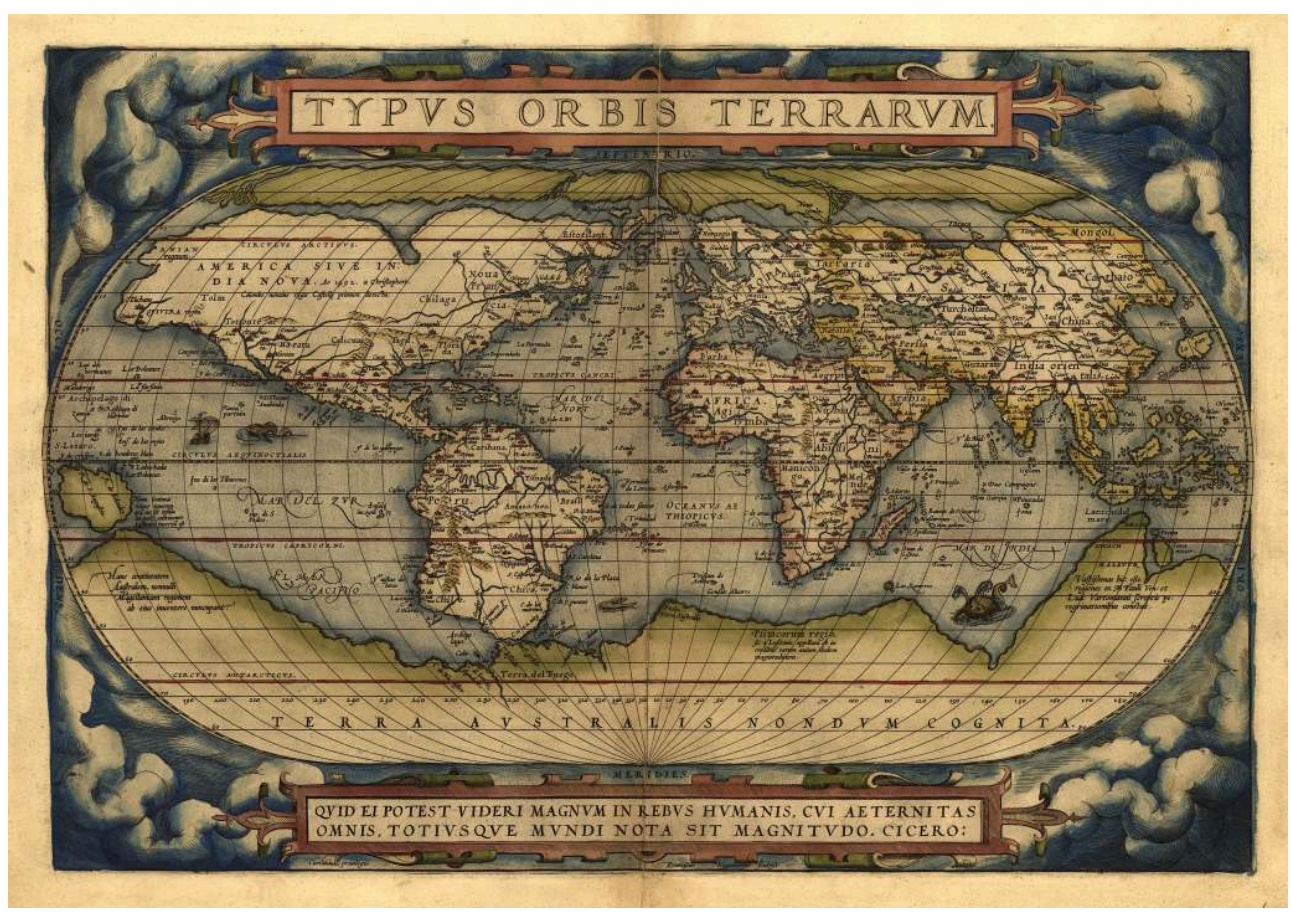

Fonte: Library of Congress. Geography and Map Division. Disponible en: https://www.loc.gov/ resource/g3200m.gct00003/?sp=18\& $r=-0.533,-0.017,1.975,0.851,0$

Desde la concepción tripartita de Mercator - Viejo Mundo o ecúmene clásico, Nuevo Mundo y continente austral - Ortelius divide el orbe de la tierra en tres partes de tierra firme: la primera llama aquella que dijimos ser dividida por los antiguos en tres (Africa, Europa y Asia), donde ha tomado su origen el género humano, como consta por la Escritura Sagrada; y la segunda la que hoy día llamamos América o India Occidental; la tercera dice que es la tierra austral, la cual algunos llaman Magellanica, por pocas riberas hasta aquí descubierta. Esta quinta parte, todavía desconocida pero verosímil, fue visualizada por los Estados excluidos del reparto luso-castellano del Nuevo Mundo como un posible ámbito de expansión comercial y política en un momento en el que el dinamismo mercantil permitía incrementar los beneficios de sus empresas ultramarinas. De este modo, el mapamundi de Ortelius se convirtió durante el último tercio del siglo XVI en una herramienta de saber-poder para el diseño de estrategias imperiales. 

no ocupadas o exploradas del hemisferio sur como objetivo de sus planes de expansión aunque los logros fueron escasos. La aventura oriental de los Ango de Dieppe terminó con el viaje de los hermanos Jean y Raoul Parmentier (1529-1530), que no llegaron más allá de Sumatra, pues los franceses prefirieron participar indirectamente en el comercio de especias posicionándose en Sevilla, Lisboa y Amberes y en los circuitos europeos de redistribución. Si bien la orientación hacia el Atlántico sur aportó mayores beneficios con la recolección del palo de Brasil desde la década de 1530, la colonia fundada en la bahía de Guanabara en 1555 -Francia antártica- solo logró mantenerse durante una década, ya que luego se impuso el monopolio portugués (Chaunú, 1984: 207-210). Aun cuando el Estado no parecía dispuesto a comprometer sus recursos en empresas inciertas, no faltaron los promotores de la exploración y el poblamiento de las supuestas tierras australes.

Si desde la década del cuarenta los cartógrafos de Dieppe proporcionaban representaciones del gran continente meridional disponible para la conquista, la obra Les Trois Mondes (1582) del historiador y autor de libros de viajes Henri Lancelot de Voisin de la Popellinière promovió directamente su descubrimiento y colonización por Francia. Aunque “ese ‘tercer mundo' no alcanzó a constituirse en un tema geográfico y, mucho menos, en una entidad geopolítica significativa o relevante" (Lois, 2008a: 192), la propuesta formulada en el contexto de la crisis política y religiosa resulta una singular combinación de saber geográfico, aspiraciones imperiales y utopía. Apoyando su argumento en la representación de la gran masa terrestre meridional de los mapamundis de Mercator y Ortelius, el autor concibe la posibilidad de una empresa que podía ofrecer a Francia posesiones territoriales que compensaran las pérdidas de Brasil y Florida e imagina la Terre Australe como un destino posible para los franceses perseguidos, un espacio de libertad en los confines del mundo (Sankey, 2003).

Por su parte, Inglaterra, que durante la primera mitad del siglo XVI no había discutido el doble monopolio de España y Portugal, desarrolla a partir de la década del setenta una política expansiva que comienza con operaciones de guerra o de piratería en los espacios oceánicos ibéricos, primero en el Atlántico y luego con incursiones en el Pacífico (Chaunú, 1984: 210-214). Si bien los objetivos del viaje de Francis Drake (1577-1580) no quedaron documentados, el recorrido efectuado entre agosto y octubre de 1578 permite suponer que se contemplara la posibilidad de costear la Terra Australis desde Tierra del Fuego hasta Nueva Guinea y las Molucas, siguiendo el mapa de Ortelius (Andrews, 1968; Spate, 2004). Tras cruzar el Estrecho en dieciséis días, ${ }^{46}$ la flota fue desplazada por un temporal hacia el sudoeste, hasta los $56^{\circ}$ o $57^{\circ} \mathrm{LS}$, luego fue llevada nuevamente a la boca occidental del estrecho y en esa posición uno de los barcos se perdió, otro regresó a Inglaterra y la nave capitana volvió hacia el sudeste. En este nuevo recorrido del litoral fueguino, Drake alcanzó la isla más austral (isla Elizabeth) y comprobó la ausencia de tierra firme hacia el sur y el este. El descubrimiento fue registrado en 1580 en un mapa del mismo Drake, reproducido en copias manuscritas probablemente no autorizadas, y en otro elaborado por el capellán de la expedición, Francis Fletcher, que muestra el término del continente sudamericano en un archipiélago, consignando la leyenda Terra Australis bene cognita (Martinic 1998). ${ }^{47}$

La irrupción de Drake en el Pacífico impuso a las autoridades coloniales ejercer un mayor control sobre la supuesta única ruta de acceso al Pacífico, y en 1579 el virrey de Perú Francisco de Toledo envió una expedición al Estrecho con el propósito de realizar 
un nuevo reconocimiento y detectar posibles asentamientos ingleses. Pedro Sarmiento de Gamboa, quien estuvo a cargo, efectuó un completo relevamiento del estrecho y se dirigió a España para participar en la elaboración del proyecto defensivo. ${ }^{48}$ Más allá de las opiniones contrarias y de las dudas sobre la configuración de Tierra del Fuego, el Consejo de Indias aprobó en 1581 un ambicioso plan que contemplaba el establecimiento de dos fuertes en la boca oriental del estrecho. La expedición dirigida por Diego Flores de Valdés, con una flota de veintitrés buques y unas tres mil personas, tenía como objetivo reforzar la defensa de los puertos del Pacífico e iniciar el poblamiento y fortificación del Estrecho; con este fin se destinaron 350 colonos y 400 soldados a los fuertes magallánicos (Luiz y Schillat, 1997: 21-22). El fundamento cartográfico del proyecto podría ofrecerlo el mapa de Joan Martines de 1578 en el que siguiendo la configuración de la gran masa de tierra austral de Ortelius - geógrafo de la corte de Felipe II desde 1575 -, utiliza dos recursos que confieren especial visibilidad a Tierra del Fuego: la coloración y el sombreado de sus costas hasta el círculo antártico y la inscripción del topónimo Terra del Fuego (Figura 9). El recurso al cambio de color, además de "establecer una distinción entre el conocimiento certero y el dato dudoso" (Lois, 2008a: 113), también podría leerse en este caso en clave geopolítica, considerando el propósito de territorializar la región magallánica sobre la que se proyectaba efectivizar el dominio hispano. Los resultados de la empresa de Sarmiento de Gamboa evidenciaron los costos de operar sobre una geografía desconocida y la divulgación de la información del viaje de Drake pronto demostró la inutilidad de mantener guarniciones en los confines inhóspitos del imperio.

Figura 9. 1578. Joan Martines, Southern South America

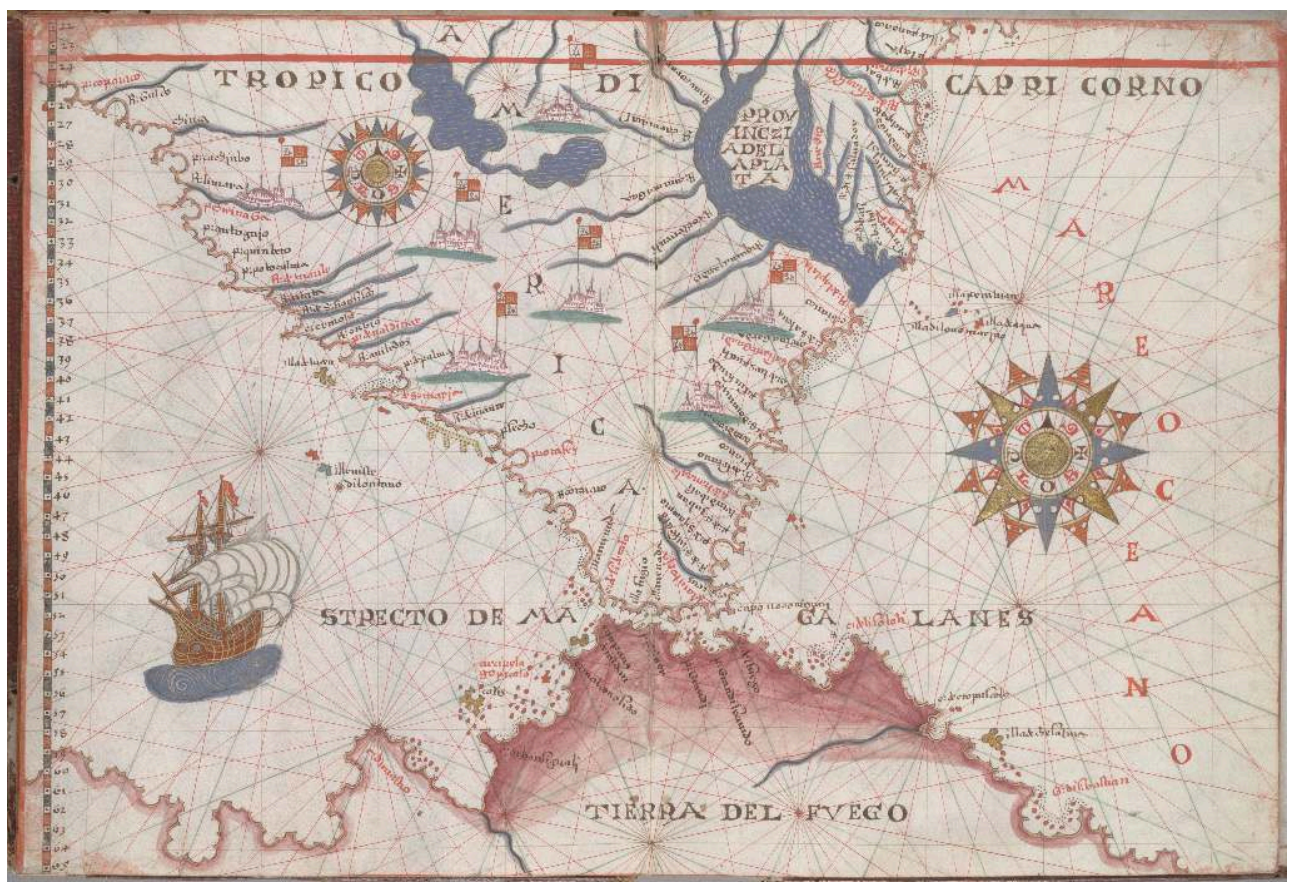

Fonte: University of California - Digital Scriptorium Huntington. Disponible en: http:// dpg.lib.berkeley.edu/webdb/dsheh/heh_brf?CallNumber=HM+33

Durante las dos últimas décadas del siglo XVI comienzan a circular los primeros mapas que representan Tierra del Fuego como un archipiélago al término de la tierra firme conocida (América) y separado de la supuesta tierra firme austral por un nuevo paso 
marítimo: Nicola van Sype (1581), Richard Hakluyt (1587) y Jodocus Hondius (1589) Otra alternativa de configuración insular planteaba a Tierra del Fuego como una isla de gran tamaño (¿isla de tierra?), descripta por Santa Cruz y representada en los mapamundis de proyección oval de dos destacados creadores de mapas italianos, B. Agnese (1544) y G. Gastaldi (1546 y 1548) (Figura 10). ${ }^{49}$

Figura 10. 1548. Giacomo Gastaldi, Carta Marina Nova tabula

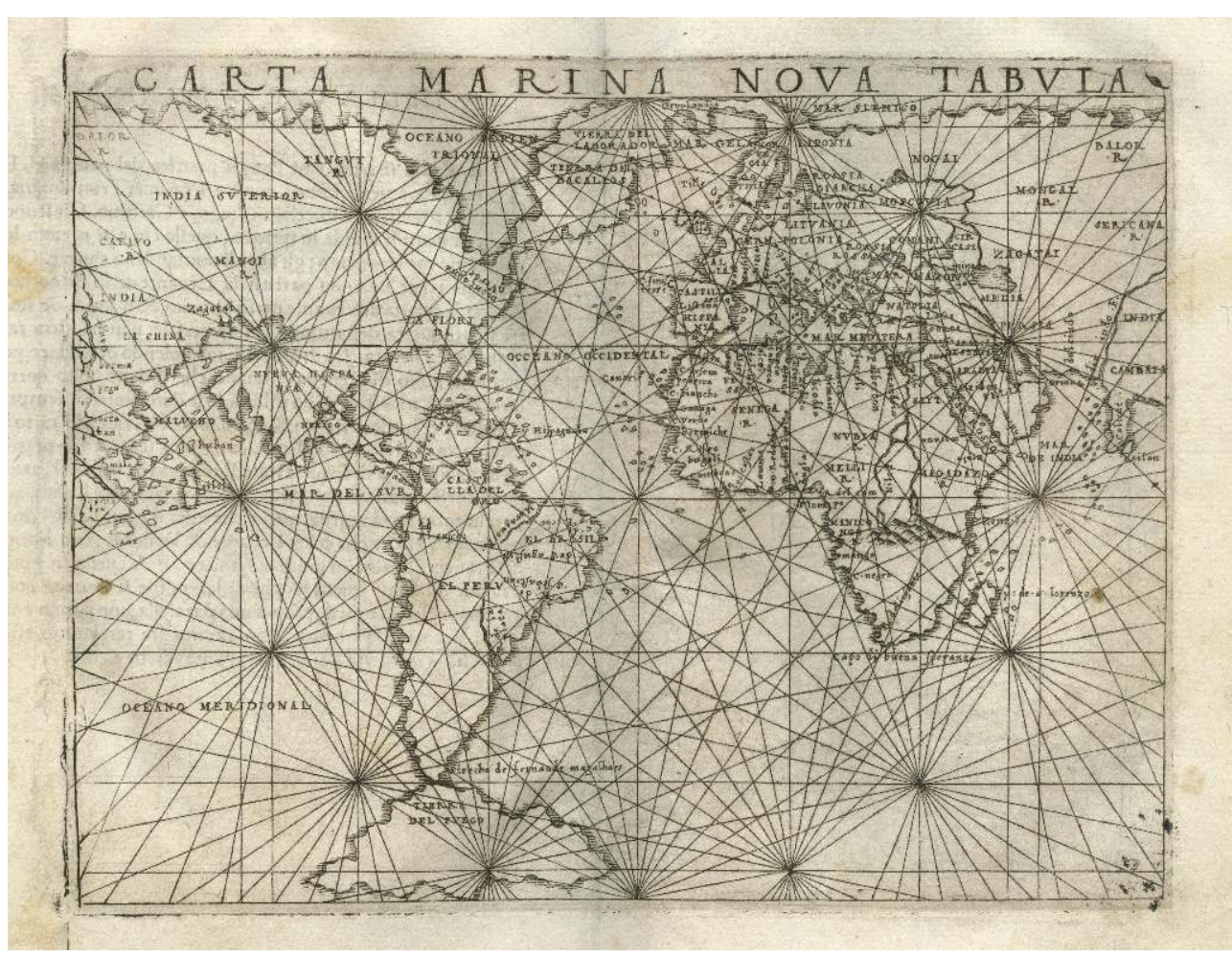

Fonte: David Rumsey Historical Map Collection. Disponible en: https://jcb.lunaimaging.com/luna/ servlet/detail/JCBMAPS 1 1 1180 101910002:Vniversale?qvq=q:gastaldi\&mi=0\&trs=5

El abandono de las colonias del estrecho y la orientación de España hacia el Pacífico no puede desvincularse del dato sobre la existencia de un vasto mar abierto más allá de Tierra del Fuego, representado en el mapa de América del Sur de Joan Martínes, incluido en su Atlas Marítimo de 1591 (Martinic, 1998). ${ }^{50}$ La estrategia imperial contempló entonces continuar desde Lima la labor exploratoria desarrollada por Álvaro de Mendaña entre 1567 y 1569, suponiéndose que las islas de Salomón, descubiertas por éste, se hallaban próximas a Nueva Guinea, que se creía tierra firme. El jesuita José de Acosta, radicado en Lima entre 1572 y 1585 e integrante del grupo de intelectuales congregados por el virrey Toledo, hace referencia a esta visión en su Historia natural y moral de las Indias (1590), donde señala además que "hay grandes conjeturas, que en la zona temperata que está al polo Antártico hay tierras prósperas y grandes, mas hasta hoy día no están descubiertas" ${ }^{51}$ El propósito era avanzar en la búsqueda de tierras australes en un área que despertaba mayores expectativas desde las referencias legendarias de Ophir y Tharsis, Java la Grande de la escuela de Dieppe y las regiones de Beach, Lucach y Maletur del mapamundi de Ortelius.

Mientras tanto, mapas de gran difusión a fines del siglo XVI y principios del XVII Ortelius (Mare Pacificum 1589), Gerard de Jode (1593), Petrus Plancius (1594), Jodocus 
Hondius (1595) y Hernando de Solís (1603) - dan cuenta de la continuidad del debate sobre la existencia y configuración de tierras en la zona templada austral como así también de las estrategias de ocultamiento y/o tergiversación de información espacial. Así se evidencia en la producción de Hondius que durante su estancia en Inglaterra maneja los datos de Drake y tras regresar a los Países Bajos en 1593 retoma la representación de Tierra del Fuego integrada a la Terra Australis. Según Wallis (1984: 147), sus mapas y globos terráqueos contribuyeron a afirmar la creencia en Holanda que Le Maire y Schouten habían sido los descubridores del paso al sur de Sudamérica (Figura 11).

Figura 11. 1595. Jodocus Hondius, Vera totius expeditionis nauticæ: descriptio D. Franc. Draci

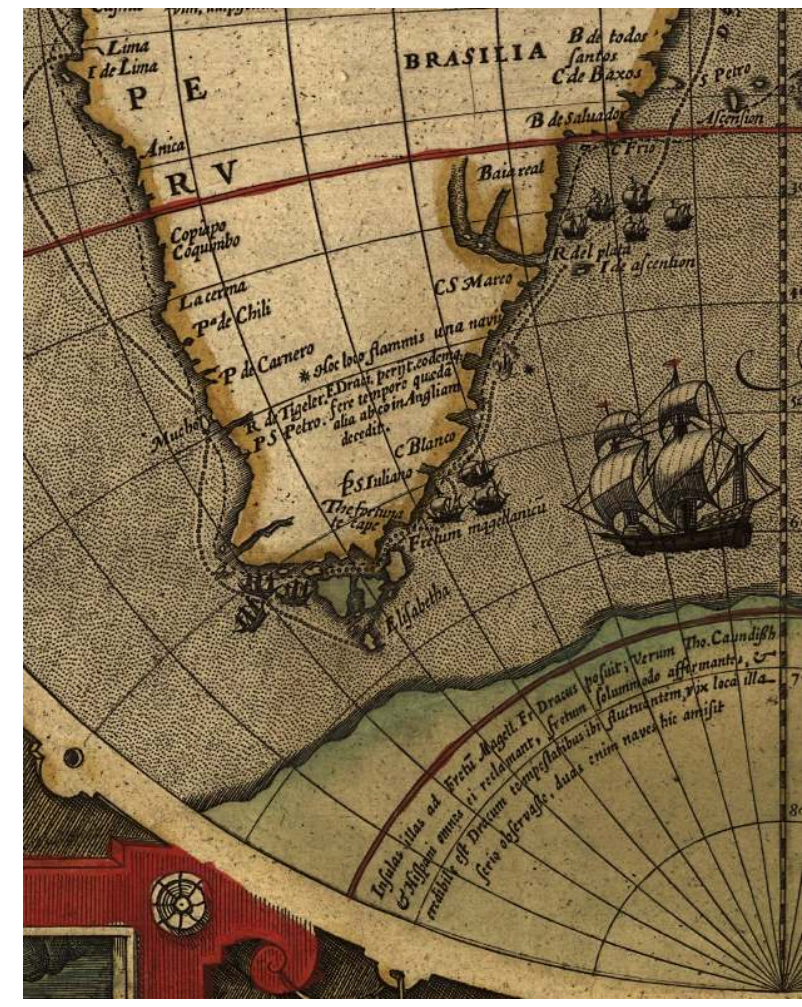

Fonte: Library of Congress. Geography and Map Division. Disponible en: http://hdl.loc.gov/loc.gmd/ g3201s.ct000130

Hacia fines del siglo XVI ingleses y holandeses incrementan su presencia en la región austral, los primeros emprendiendo una serie de viajes corsarios a través del estrecho con más costes que beneficios y los segundos efectuando reconocimientos del canal interoceánico por el interés de las compañías comerciales distribuidoras de especias de utilizar esta vía para acceder a los centros productores de las Indias Orientales (Chaunú, 1984). Los resultados de las primeras expediciones holandesas que recorrieron la región magallánica en 1599 demostraron que esta ruta, aunque más corta que la africana, resultaba sumamente riesgosa, y los viajes de exploración se suspendieron durante más de una década (Martinic, 1999). La necesidad de hallar vías de navegación alternativas a la del Estrecho y la del Cabo de Buena Esperanza, reservadas por los Estados Generales de Holanda a la Compañía de las Indias Orientales, estimuló a la Compañía Austral de Hoorn a proseguir la exploración y, en 1616, la expedición dirigida 


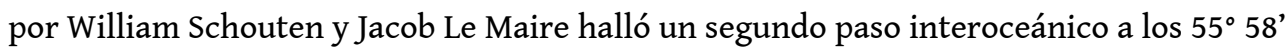
de latitud sur.

53 La confirmación de la insularidad de Tierra del Fuego con el descubrimiento de la ruta del Cabo de Hornos a través del pasaje Drake y, tres años más tarde, y la primera circunnavegación del archipiélago fueguino por los capitanes Bartolomé y Gonzalo Nodal (1618-1619) permitió cerrar el secular debate sobre la entidad de las tierras magallánicas sin debilitar la hipótesis del continente austral.

\section{A modo de conclusión: la frontera austral}

La exploración de las costas meridionales de América con el propósito de hallar un paso marítimo hacia Oriente posibilitó dilucidar la entidad geográfica de las tierras descubiertas en el Atlántico y al mismo tiempo abrió nuevos interrogantes sobre la configuración del hemisferio sur y la existencia de una ecúmene austral. El debate científico sobre la imagen del mundo y la habitabilidad de las distintas regiones es indisociable de los objetivos y necesidades de la expansión ultramarina. La cartografía elaborada durante el siglo XVI muestra esta estrecha relación entre saber y poder, al expresar tanto las concepciones cosmográficas y geográficas desde las que se interpretó la nueva información espacial como los presupuestos políticos e ideológicos que condicionaron las representaciones del espacio.

La expedición de Magallanes - Elcano confirmó que el buscado paso hacia la especiería era un estrecho entre la tierra firme conocida - América - y otras tierras australes desconocidas - Tierra del Fuego - que, desde la concepción de un hemisferio sur terrestre, fueron representadas como parte de la masa continental prefigurada en las fuentes clásicas y medievales y conjeturada por la necesidad cosmográfica de equilibrio y simetría entre los dos hemisferios. Desde la tercera década del siglo XVI circularon mapas que representan un extenso continente austral con distintas formas y dimensiones pero que tienen en común la hipotetización de sus contornos a partir de las costas conocidas de Tierra del Fuego, Australia y Nueva Guinea.

56 Las interpretaciones sobre la naturaleza territorial de la "quinta parte" o "tercer mundo" de los mapamundis de Mercator y Ortelius se construyeron a partir de la especulación teórica, la imaginación creativa y los datos empíricos producidos por las primeras expediciones que recorrieron los mares australes. Mientras las noticias que circularon sobre las tierras descubiertas en el Pacífico Sur alimentaron la creencia en un continente con recursos de interés comercial, la información sobre el extremo meridional de América resultó desde el inicio menos estimulante y dio pie a visiones sobre la esterilidad, la hostilidad del clima y la naturaleza salvaje de sus habitantes. El discurso cartográfico jugó un papel importante en la permanencia de estas representaciones al proporcionar un conjunto de referencias sobre las que se construye una imagen de Patagonia y Tierra del Fuego desde las creencias y expectativas de los europeos como un territorio de incierta utilidad.

57 La percepción de las condiciones de habitabilidad junto a las riesgosas condiciones de navegabilidad de la ruta magallánica explica el escaso avance exploratorio y colonizador. Aunque el dominio colonial se mantuvo en el plano formal, excepto durante la efímera ocupación española de la costa septentrional del Estrecho, la cartografía reforzó el proceso de territorialización del extremo sur continental y de las 
tierras adyacentes inscribiendo en el espacio abstracto lugares, itinerarios, sujetos, productos, paisajes y eventos, expresando a través de diversas decisiones de forma y contenido la apropiación simbólica del territorio y legitimando intencionalidades geopolíticas.

La confirmación del carácter insular de las tierras situadas al sur del estrecho de Magallanes debilitó las expectativas de España sobre los beneficios del control del canal interoceánico, contemplándose la búsqueda de nuevas tierras más promisorias en términos de rentabilidad económica que la inhóspita y apenas poblada Patagonia.

El descubrimiento de una ruta marítima alternativa a la del Estrecho a través del Cabo de Hornos no cambió la (des)valorización de la región, y la desvinculación de Tierra del Fuego del supuesto continente austral orientó la exploración hacia otras regiones del Pacífico. Si bien los resultados de las expediciones fueron desalentadores, la búsqueda de evidencias de "otro continente posible" no se detuvo hasta bien avanzado el siglo XVIII cuando, tras comprobarse la inhabitabilidad de las tierras situadas más allá del círculo antártico, Tierra del Fuego y los archipiélagos australes devinieron la frontera entre lo conocido y lo desconocido, entre la zona templada habitable y la frígida que se presume inhabitable, en definitiva, como la frontera moderna del ecúmene.

\section{BIBLIOGRAPHY}

Andrews, Kenneth R. (1968). “The Aims of Drake's Expedition of 1577-1580”. The American Historical Review, v. 73, n. 3, pp. 724-741.

Besse, Jean-Marc (2010). "Philologie et cartographie au XVIe siécle: la critique de l'histoire dans le Parergon et le Thesaurus geographicus d'Abrabam Ortelius". $3^{\circ}$ Simpósio Iberoamericano de História da Cartografía. Agendas para História da Cartografia Iberoamericana, Sao Paulo, Universidade de Sao Paulo.

Buisseret, David (2003). La revolución cartográfica en Europa. 1400-1800. La representación de los nuevos mundos en la Europa del Renacimiento. Barcelona: Paidós.

Calander, John (1967) Terra Australis cognita or voyages to the Terra Australis. T. 1 [facsímil del original, Edimburgo, 1766], Ámsterdam.

Cattaneo, Angelo (2009). "Réflexion sur les climats et les zones face á l'expansion des Xve et XVIe siécles”. Le Monde des cartes, n. 199, pp. 7-21.

Cerezo Martínez, Ricardo (1994). La cartografía marítima española en los siglos XIV, XV y XVI. Madrid: Consejo Superior de Investigaciones Científicas.

Chartier, Roger (1996). El mundo como representación. Historia cultural: entre práctica y representación. Barcelona: Gedisa.

Chaunú, Pierre (1984). Conquista y explotación de los nuevos mundos (siglo XVI). Barcelona: Labor.

Day, John T. (1988). “The New World in Maps: The First Hundred Years”. The Newberry Library. 
Fernadez de Navarrete, Martín (1946). Colección de los viajes y descubrimientos que hicieron por mar los españoles. Buenos Aires: Guarania.

Gandía, Enrique de (1946). Historia crítica de los mitos de la conquista americana. Madrid: J. Roldán. Guedes, Max J. (2009). “A carta náutica de Piri Reis (Piri Reis Haritasi), 1513”. Anais do Museu Paulista, v. 17, n. 1, pp. 95-111.

Haesbaert, Rogerio; Limonad, Ester (2007). “El territorio en tiempos de globalización”. Revista Electrónica de Ciencias Sociales Aplicadas, v. 1, n. 2.

Harley, John B. (2005). La nueva naturaleza de los mapas. Ensayos sobre la historia de la cartografía. México: Fondo de Cultura Económica.

Hiatt, Alfred (2007). “The Map of Macrobius before 1100”. Imago Mundi. The International Journal for the History of Cartography, v. 59, n. 2, pp. 149-176.

Kagan, Richard L. (2005). "La Luna de España: Mapas, ciencia y poder en la época de los Austrias". Pedralbes, n. 25, pp. 171-190.

Levillier, Roberto (1956). “Mundus Novus”. Anales de la Universidad de Chile, n. 104, pp. 197-255.

Lévy, Jacques (2006). “Geografía y mundialización”. En: Hiernaux, Daniel; Lindón, Alicia (Dir.). Tratado de Geografía Humana. México: Anthropos.

Lois, Carla (2008a). Plus Ultra Equinoctialem. El descubrimiento del hemisferio sur en mapas y libros de ciencia en el Renacimiento. Tesis Doctoral. Facultad de Filosofía y Letras, Universidad de Buenos Aires

Lois, Carla (2008b). “América quarta pars: ¿isla o continente? El debate conceptual sobre el estatus geográfico del Nuevo Mundo en el siglo XVI”. Fronteras de la Historia, Instituto Colombiano de Antropología e Historia, v. 13, n. 2, pp. 259-279.

Lois, Carla (2010). "Quinta Pars o Terrae Incognitae? La cuestión de la verosimilitud en la representación cartográfica de lo desconocido”. $3^{\circ}$ Simpósio Iberoamericano de História da Cartografía. Agendas para História da Cartografia Ibernoamericana, Universidad de Sao Paulo, Sao Paulo.

López Levi, Liliana (2018). "Imaginación geográfica y apropiación territorial: exploración, divulgación científica y narración literaria en el siglo XIX”. Imagonautas. Revista Interdisciplinaria sobre Imaginarios Sociales, n. 12, pp. 1-18.

Luiz, María Teresa; Schillat, Monika (1997). La frontera austral. Tierra del Fuego 1520-1920. Cádiz: Servicio de Publicaciones de la Universidad de Cádiz

Martín-Merás, María Luisa (1993). Cartografía Marítima Hispana: La imagen de América. Madrid: Lunwerg.

Martinic Beros, Mateo (1981). “Estrecho de Magallanes, territorio marítimo chileno”. Anales del Instituto de la Patagonia, Punta Arenas (Chile), v. 12, pp. 7-29.

Martinic Beros, Mateo (1983). “El Reino de Jesús. La efímera historia de una gobernación en el estrecho de Magallanes (1581-1590)”. Anales del Instituto de la Patagonia, v. 14, pp. 7-32.

Martinic Beros, Mateo (1998). "Drake y el descubrimiento de la insularidad fueguina". En: Anales del Instituto de la Patagonia, v. 14, n. 26, pp. 5-22

Martinic Beros, Mateo (1999). Cartografía Magallánica 1523-1945. Punta Arenas: Ediciones de la Universidad de Magallanes. 
McIntosh, Gregory (2000). The Piri Reis Map of 1513. Georgia: University of Georgia Press.

Mignolo, Walter (1995). The darker side of the Renaissance: literacy, territoriality and colonization. Ann Arbor: University of Michigan Press.

Nocetti, Oscar R.; Mir, Lucio B. (1997). La disputa por la tierra. Tucumán, Río de la Plata y Chile (1531-1822). Buenos Aires: Sudamericana.

O'Gorman, Edmundo (1995). La invención de América. México: Fondo de Cultura Económica.

Padrón, Ricardo (2004). The Spacious Word: Cartography, Literature, and Empire in Early Modern Spain. Chicago: University of Chicago Press.

Padrón, Ricardo (2010) “Las Indias olvidadas: Filipinas y América en la cartografía imperial española". $3^{\circ}$ Simposio Iberoamericano de História da Cartografía, Sao Paulo, Universidade de Sao Paulo.

Pigafetta, Antonio (1963). Primer viaje en torno del globo. Madrid: Espasa-Calpe.

Quintero, Silvina (2000). "Pensar los mapas. Notas para una discusión sobre los usos de la cartografía en la investigación social”. En: Escolar, Cora (Comp.). Topografías de la investigación. Métodos, espacios y prácticas profesionales. Buenos Aires: Eudeba.

Raffestin, Claude (1993). Por uma Geografia do Poder. Sao Paulo: Editora Ática.

Roa-de-la-Carrera, Cristián (2002) "El Nuevo Mundo como problema de conocimiento y el discurso geográfico del siglo XVI". Hispanic Review, v. 70, n. 4, pp. 557-580.

Rodamilans Ramos, Fernando (2010). “Crónica de Pedro Fernández de Quirós: Historia del descubrimiento de las regiones austriales hecho por el General Pedro Fernández de Quirós”. Ab Initio, n. 1, pp. 104-122.

Romano, Ruggiero; Tenente, Alberto (1979). Los fundamentos del mundo moderno. Edad Media tardía, Renacimiento, Reforma. Madrid: Siglo XXI.

Sánchez Martínez, Antonio (2010). "La institucionalización de la cosmografía americana: la Casa de la Contratación de Sevilla, el Real y Supremo Consejo de Indias y la Academia de Matemáticas de Felipe II". Revista de Indias, v. 70, n. 250, pp. 715-748.

Sánchez, Antonio (2010). "La voz de los artesanos en el Renacimiento científico: cosmógrafos y cartógrafos en el preludio de la 'Nueva Filosofía Natural”. Arbor. Ciencia, Pensamiento y Cultura, v. 186, n. 743, pp. 449-460.

Sankey, Margaret (2003). "The French and Terra Australis". The Journal of the Sydney University, v. 25, pp. 26-63.

Spate, Oskar (2004) The Spanish Lake: The Pacific since Magellam. Australia: ANU Press.

Staszak, Jean F. (2012). "La construcción del imaginario occidental del 'allá y la fabricación de las 'exotica': el caso de los toi moko maoríes”. En: Lindón, Alicia; Hiernaux, Daniel (Dir.). Geografías de lo imaginario. Barcelona: Anthropos - México, Universidad Autónoma Metropolitana, pp. 177-203.

Stevenson, Edward L. (1904). "Martin Waldseemuller and the Early Lusitano-Germanic Cartography of the New Word Autor(s)". Bulletin of the American Geographical Society, v. 36, n. 4, pp. 193-215.

Stevenson, Edward L. (1921). Terrestrial and celestial globes: their history and construction, including a consideration of their value as aids in the study of geography and astronomy. New Haven: Hispanic Society of America by the Yale University Press. 
Tanzi, Héctor J. (1985). “El continente antártico y la Tierra del Fuego”. Revista de Historia de América, n. 100, pp. 13-54.

Van Duzer, Chet (2007). “Cartographic Invention: The Southern Continent on Vatican MS Urb Lat. 274, Folios 73v-74r (c. 1530)". Imago Mundi. The International Journal for the History of Cartography, v. 59, n. 2, pp. 193-222.

Van Duzer, Chet (2008). “A Newly Discovered Fourth Exemplar of Francesco Rosselli’s Oval Planisphere of c. 1508". Imago Mundi. The International Journal for History of Cartography, v. 60, n. 2, pp. 195-201.

Vignolo, Paolo (2003). "Nuevo Mundo: ¿un mundo al revés? Las antípodas en el imaginario del Renacimiento”. En: Bonnett, Diana; Castañeda, Felipe (Eds.). El Nuevo Mundo. Problemas y debates. Bogotá: Uniandes.

Wallis, Helen (1984). “The Cartography of Drake's voyage”. En: Thrower, Norman (Ed.). Sir Francis Drake and the famous voyage, 1577-1589. Los Angeles: University of California Press.

Zuber, Mike (2011). "The Armchair Discovery of the Unknown Southern Continent: Gerardus Mercator, Philosophical Pretensions and a Competitive Trade”. Early Science and Medicine, v. 16, n. 6, pp. 505-541.

\section{APPENDIXES}

\section{Fuentes cartográficas}

1482. Ptolomeo, Edición Ulm, World Map. Repositorio: John Carter Library Map Collection.

1492. Martin Behaim, Erdapfel Repositorio: David Rumsey Historical Map Collection.

1493. Anónimo, Laon globe. Repositorio: Jim Seibold. Disponible en: www.cartographicimages.net.

1502. Juan de la Cosa, Mapa universal con la representación del nuevo mundo. Repositorio: Ibero-Amerikanischen Instituts Digitalen Sammlungen.

1502. Cantino, Planisphère. Repositorio: Bibliotèque Nationale de France, Départament des Cartes et Plans.

1506. Nicolaus de Caverio, Planisphère nautique. Repositorio: Bibliotèque Nationale de France, Départament des Cartes et Plans.

1507. Martin Waldseemüler, Universalis cosmographia secundum Ptholomaie traditionem et Americi Vespucii alioru[m]que lustratione. Repositorio: Library of Congress Geography. Washington, D.C.

1508. Francesco Rosselli, Mapamundi, c. 1508. Repositorio: Royal Museums Greenwich National Maritime Museum.

1513. Henricus Glareanus, Hemisferio austral, c. 1513. Repositorio: John Carter Library Map Collection.

1513. Piri Reis, Chart of the Ocean Sea. Repositorio: Jim Seibold. Disponible en: www.cartographic-images.net. 
1515. Johannes Schöner, Globe. Repositorio: Yale University Library Beinecke Digital Collections.

1520. Johannes Schöner, Globus. National Library of Finland - Doria.

1523. Johanes Schoner, Terrestrial globe. Repositorio: National Library of Australia Digital Collections.

1527. Robert Thorne, Orbis Vniuersalis Descriptio. Repositorio: John Carter Library Map Collection.

1529. Diego Ribero, Carta universal. Repositorio: National Library of Australia Digital Collections.

1531. Oronce Fine, Nova, et integra vniversi orbis descriptio. Repositorio: Library of Congress. Geography and Map Division.

1535. Anónimo, Nancy Globe. Repositorio Leventhal Map Center - Boston Public Library 1538. Gerardus Mercator, Double Cordiform Map of the World. Repositorio: David Rumsey Historical Map Collection.

1541 Gerardus Mercator, Sphères terrestre et céleste. Repositorio: National Library of Australia.

1542 Alonso de Santa Cruz, World Map. Repositorio: National Library of Australia.

1544. Batista Agnese, Atlas. Repositorio: Biblioteca Digital Hispánica - Biblioteca Nacional de España.

1545. Alonso de Santa Cruz, Islario general de todas las islas del mundo. Repositorio: Biblioteca Digital Hispánica - Biblioteca Nacional de España.

1546. Giacomo Gastaldi, Universalle. Repositorio: John Carter Brown Map Collection. 1546. Pierre Desceliers, World Map. Repositorio: National Library of Australia. 1547. Vallard, Atlas. Repositorio: University of California - Digital Scriptorium Huntington.

1548. Giacomo Gastaldi, Carta Marina Nova tabula, Repositorio: David Rumsey Historical Map Collection.

1554. Michelle Tramezzino, Map of the world in hemispheres. Repositorio: John Carter Library Map Collection.

1555. Guillaume Le Testu, Cosmographie universelle. Repositorio: Bibliotèque Nationale de France, Départament des Cartes et Plans.

1562. Diego Gutiérrez, Americae sive qvartae orbis partis. Repositorio: Library of Congress. Geography and Map Division.

1569. Gerardus Mercator, Nova_et_aucta_orbis_terrae. Repositorio: Bibliotèque Nationale de France, Départament des Cartes et Plans.

1570. Abraham Ortelius, Typus Orbis Terrarum. Repositorio: Library of Congress. Geography and Map Division.

1578. Joan Martines, Southern South America. Repositorio: University of California Digital Scriptorium Huntington. 
1582. Lancelot Voisin de La Popelinière, Les Trois Mondes. Repositorio: John Carter Library Map Collection.

1587. Richard Hakluyt, Novus Orbis. Repositorio: Beinecke Rare Book and Manuscript Library, Yale University.

1589. Abraham Ortelius, Maris Pacifici. Repositorio Leventhal Map Center - Boston Public Library.

1589. Jodocus Hondius, Americae novissima. Repositorio: Bibliotèque Nationale de France, Départament des Cartes et Plans.

1593. Cornelis De Jode, Speculum orbis terrarum. Repositorio: Bibliotèque Nationale de France, Départament des Cartes et Plans.

1594. Petrus Plancius, Orbis terrarum typus. Repositorio: National Library of Australia.

1595. Jodocus Hondius, Vera totius expeditionis nauticæ: descriptio D. Franc. Draci. Repositorio: Library of Congress. Geography and Map Division.

1603. Hernando de Solis, Typus Orbis Terrarum. Repositorio: John Carter Library Map Collection.

\section{NOTES}

1. 1 Sobre las características de los mapas del siglo XVI y los modos de conceptualizar el espacio en la transición de la cartografía medieval a la moderna, cf. Padrón (2004) e Buisseret (2003).

2. 2 Las fuentes cartográficas - mapas manuscritos e impresos de diferentes géneros: político, científico y de divulgación - fueron seleccionadas a partir de la posibilidad de ser contextualizadas en un corpus de producción, identificando autores e instituciones promotoras, fuentes de información, presupuestos filosóficos, epistemológicos y políticos. Nos servimos de imágenes reproducidas en estudios de cartografía histórica regional y/o disponibles en los catálogos online de distintos repositorios virtuales europeos, americanos y australianos. Los estudios referidos a la cartografía del Renacimiento y a diversos aspectos vinculados a ésta ofrecen elementos sobre los contextos de producción y circulación de los mapas y proposiciones sugerentes para la construcción de claves de lectura.

3. 3 Desde la perspectiva de la historia cultural, el concepto de representaciones alude a los esquemas de percepción, cognición y valoración que conforman los sistemas de pensamiento y juicio desde los cuales se construyen significaciones y se produce la "realidad" articulando lo empírico, lo simbólico y lo imaginario. Cf. Chartier (1996). Debe distinguirse este significado del uso corriente de la noción de representación en la teoría cartográfica tradicional que apela la correspondencia entre universo material y universo simbólico, realidad y representación. Cf. Quintero (2000: 187-217).

4. 4 En la aproximación a este proceso nos servimos del estudio de Carla Lois sobre la producción de imágenes cartográficas y conocimiento geográfico del hemisferio sur durante el siglo XVI. La autora presenta un exhaustivo estado de la cuestión sistematizando las cuestiones que posibilitaron la renovación de la teoría cartográfica y los problemas abordados en las investigaciones sobre la cartografía renacentista. Citamos Lois (2008a).

5. 5 Durante el siglo XVI se opera el tránsito de una primera fase de mundialización que descansa en la búsqueda de información y la pretensión de realizar transacciones comerciales a otra que durante la segunda mitad de la centuria es dinamizada por los proyectos de conquista y control territorial de los Estados de Europa occidental. Cf. Lévy (2006: 282). 
6. 6 Se trata de un proceso de construcción de nuevos saberes e imaginarios espaciales en el tránsito de una concepción basada en la idea clásica del ecumene como mundo conocido y habitado a una representación del globo terrestre con distintas partes, continentes o mundos que admite la posibilidad de zonas habitables o habitadas, aunque desconocidas. Cf. Lois (2008a: 39).

7. Entendemos por imagen territorial las representaciones construidas por un actor sintagmático - según Raffestin (1993), aquel que realiza un proyecto o programa en cualquier nivel - para legitimar concepciones, creencias, intereses e intervenciones. Esta construcción, en la que participan la literatura científica y de viajes y la cartografía, constituye la dimensión simbólica de la apropiación territorial. La imagen territorial condiciona las formas de pensar y valorar el espacio y, en la mediana o larga duración, configura imaginarios geográficos e identidades territoriales. Cf. Levi (2018) y Staszak (2012).

8. Desde las actuales re-conceptualizaciones que conciben al territorio como una construcción histórica-social, condición y resultado de las relaciones sociedad-naturaleza, los procesos de territorialización se abordan teniendo en cuenta la articulación de dimensiones materiales y simbólicas - jurídico-política, económica y cultural -, considerando las prácticas y las representaciones, las estrategias y los medios utilizados por distintos grupos para apropiarse o mantener cierto dominio funcional y simbólico sobre una porción del espacio geográfico. Cf. Raffestin (1993) y Haesbaert y Limonad (2007).

9. 9 Identificamos escalas, proyecciones, puntos extremos, red de latitudes y longitudes, títulos, leyendas, toponimia y otras referencias verbales, formas, colores y texturas, dibujos y pictogramas. Cf. Harley (2005).

10. 10 Consideramos los textos incluidos en los mapas y que los configuran - leyendas y referencias - y los textos descriptivos que en algunos casos los acompañan y con los que guardan una estrecha relación - atlas, islarios, cosmografías y relaciones.

11. 11 La Casa da India de Lisboa (1500) y la Casa de Contratación de Sevilla (1503), aunque no se crearon como instituciones científicas, se convirtieron en los primeros centros de ciencia aplicada de carácter cosmográfico, cartográfico y náutico de Europa. La Casa de Contratación y el Consejo de Indias (1524) mantuvieron una estrecha relación política y científica, regulando éste la vertiente científica de la Casa. Con la creación del cargo de Cosmógrafo-Cronista Mayor de Indias en 1571 se alcanzó la más fuerte vinculación entre ciencia y poder político. Cf. Sánchez Martínez (2010: 715-748).

12. 12 Lois señala que "no es claro que exista un vínculo tan directo entre el continente austral del quinientos y las tierras del alejandrino" y observa la necesidad de "explorar más sistemáticamente si esa geografía clásica, aunque fuertemente reformulada, ha sido una fuente de inspiración para hacer aparecer en el mapa ese continente austral en el Renacimiento" (Lois, 2008a: 265).

13. 13 Desde la concepción de las cuatro partes o continentes de Crates de Mallos (siglo II a.C.), Macrobio (siglo V d.c.) también teoriza sobre la existencia de una gran tierra austral pero independiente de la africana. Su obra tuvo gran influencia durante la Edad Media y fue una fuente importante en las discusiones cosmográficas y geográficas del siglo XVI. Cf. Hiatt (2007: 149-176).

14. 14 De acuerdo a esta teoría, formulada por Parménides (siglo V a.C.) y desarrollada por Eratóstenes (siglo II a.C.), el globo se dividía siguiendo los paralelos de referencia astronómica en cinco zonas climáticas: dos frías próximas a los polos, dos templadas intermedias y una zona cálida o tórrida a ambos lados del ecuador hasta los trópicos. Las primeras se consideraban inhabitables por el excesivo frío y la última por el extremo calor. Esta concepción fue expuesta por el cardenal Pierre d'Ailly en su Imago Mundi (1410), fuente de consulta de los intelectuales del Renacimiento. Sobre las zonas climáticas en el corpus de mapas Macrobio, cf. Hiatt (2007).

15. 15 Roger Bacon (1268) y John Mandeville (1356) postulaban la habitabilidad de la zona tórrida (Lois, 2008a: 68-69). 
16. 16 El imaginario medieval, particularmente la cosmología cristiana que no concebía la existencia de seres humanos excluidos de la descendencia de Adán y del mensaje de los Evangelios, pobló el continente antípoda con las razas monstruosas de Plinio (siglo I d.c.) y otros seres fantásticos que nutrieron un gran repertorio de mitos y leyendas (Vignolo, 2003). Asimismo, "la existencia de zonas lejanas con climas diferentes al europeo y las dudas que existían sobre su habitabilidad favorecieron el establecimiento de relaciones causales entre clima y monstruosidad, especialmente en el tardío medioevo" (Lois, 2008a: 148).

17. 17 Según Roa-de-la-Carrera (2002), Vespucio entra en diálogo con una tradición de discursos sobre espacios desconocidos, confirma o cuestiona las ideas de los antepasados con la aspiración de completar la imagen del mundo procedente de un cuerpo de saberes asumidos, aceptados y compartidos.

18. 18 Se trata de la carta dirigida desde Lisboa a Lorenzo Pier Francesco de Médicis en 1502, publicada en latín un año después como opúsculo titulado Mundus Novus (París, 1503) y con numerosas re-ediciones, doce en 1504, veintidós en los tres años posteriores y alrededor de cincuenta antes de 1550. Cf. Levillier (1956), Romano y Tenente (1979: 178).

19. 19 Los viajes de Vespucio desataron una controversia sobre la latitud sur alcanzada y las costas recorridas o avistadas. Mientras la cartografía oficial de España y Portugal sólo representan América hasta los $35^{\circ}$ LS, los mapas de Waldseemüller (1507), Roselli (1508) y Glareanus (1513) interpretan el relato del tercer viaje representando la costa americana con un rumbo sudoeste hasta los $50^{\circ}$ LS aproximadamente, es decir, aceptan la latitud declarada por Vespucio ( $\left.52^{\circ} \mathrm{LS}\right)$ pero no el rumbo (sudeste). Si el objetivo de la expedición era la búsqueda de un paso hacia el oeste, puede suponerse que el derrotero hacia el sudoeste, superando el límite de Tordesillas $\left(32^{\circ} \mathrm{LS}\right)$, habría sido ocultado deliberadamente por la corte portuguesa para evitar conflictos diplomáticos con España ya que significaba explorar dentro del hemisferio español.

20. 20 Lois (2008a) señala que "esta forma de recortar la superficie cartografiada fue uno de los primeros recursos a los que se apeló para dejar vacíos en los mapas: no había una mancha desierta dentro del mapa sino que se recurría a las propiedades de un espacio plano cuya extensión era previamente definida según principios geométricos de la esfera ( $360^{\circ}$ de longitud y $180^{\circ}$ de latitud) y, para sugerir que el mundo era más extenso que aquel que se representaba en el mapa y que no se conocía en su totalidad, se diseñaba sólo una parte".

21. 21 Fischer, Joseph y von Weiser, Franz, Cosmographiae introductio of Martin Waldseemüller, New York, United States Catholic Historical Society, IV, 1907. Repositorio: Kelly- Universidad de Toronto, Digital. La Lettera di Amerigo Vespucci delle isole nuovamente trovate in quarto suoi viaggi, carta dirigida por Vespucio a Piero Soderini, fue incluida como apéndice en la Cosmographiae introductio. Cf. Roa-de-la-Carrera (2002: 568-569).

22. Cf. Van Duzer (2008: 195-201).

23. El texto de Schöner que acompaña el mapa de 1515 -Luculentissima quaedan Terrae totius Descriptio - hace referencia a la información proporcionada a un agente de la casa bancaria Welser, en Madeira, por navegantes portugueses que habrían recorrido un estrecho al sur de las tierras conocidas de América. Cf. Stevenson (1904: 193-215) y Tanzi (1985: 13-54).

24. Las primeras expediciones que buscan en el Río de la Plata un paso hacia el oeste fueron dirigidas por Cristóbal de Haro y Nuño Manuel (1514) y Juan Díaz de Solís (1515-1516). Las instrucciones elaboradas en 1514 para este último establecían costear el litoral de Brasil hacia el sur y, al llegar al fin de la tierra firme, poner rumbo noreste o noroeste hasta llegar a "las espaldas de Castilla del Oro", es decir, a las costas del Mar del Sur descubiertas por Balboa en 1513 (Fernández de Navarrete, 1946).

25. Relación de Maximiliano Transilvano. En J.T. Medina, Colección de documentos inéditos para la historia de Chile, T. I, 1896, p. 264. Repositorio: Memoria Chilena - Biblioteca Nacional Digital de chile. 
26. Según los cálculos de longitud del cosmógrafo Rui Falero que estimaban una extensión menor del Mar del Sur, las Molucas se situaban dentro de la jurisdicción castellana del Tratado de Tordesillas. Señala Padrón que entre el mapa de Walseemüller de 1507 y el planisferio de Diego Ribero de 1529 se observa un crecimiento en el ancho del Pacífico, de 80 grados de longitud a 134. Cf. Padrón (2010). Considerando que Pedro y Jorge Reinel participaron en la producción de los mapas de la expedición, es posible que el derrotero propuesto por Magallanes a Carlos V se diseñara sobre el mapamundi de Reinel de 1519 que representa las tierras conocidas hasta el Río de la Plata. Cf. Cerezo Martínez (1994).

27. Relación de Maximiliano Transilvano, op. cit. p. 264. Antonio de Pigafetta menciona en su relación del viaje que Magallanes habría visto representado un estrecho en un mapa de Martín de Bohemia (Behaim). Cf. Pigafetta (1963: 59). Algunos autores plantean que el mapa que habría guiado a Magallanes fue el Schöner de 1515 que representa un paso marítimo a los $40^{\circ} \mathrm{o} 45^{\circ} \mathrm{LS}$ entre el Nuevo Mundo y un continente anular en la zona templada austral. Cf. de Gandía (1946) y Martinic (1992).

28. Según Fernández de Navarrete la propuesta de Magallanes de acceder a Oriente por el oeste "pareció tan ideal como dificultosa, por juzgarse entonces que el continente americano (aun no enteramente reconocido) se extendía de norte a sur, sin interrupción y sin dejar paso o estrecho que se pudiese atravesar para la comunicación de los dos mares" (Fernández de Navarrete, 1946: 36-37). El mapa de Lopo Homen de 1519, incluido en el Atlas Miller, representaría esta alternativa, planteando una masa de tierra que, rodeando el Polo sur, unía América y el sudeste de Asia.

29. López de Gomara, Francisco, Historia General de las Indias, 1554. Repositorio: Biblioteca Digital Hispánica -Biblioteca Nacional de España. Antonio de Pigafetta se refiere a esta alternativa señalando: "En caso de que no hubiéramos descubierto el estrecho para pasar de un mar a otro, el capitán general había determinado continuar la ruta al Sur hasta los $75^{\circ}$ de latitud meridional, donde durante el estío no hay noche, o, al menos muy poca, como no hay día en el invierno" (Pigafetta, 1963: 62).

30. Aunque Pigafetta elaboró en 1522 un mapa destinado a acompañar la relación del viaje en el que representa el estrecho de los Patagones o Estrecho Patagónico, se considera a la Carta Universal o Padrón Real de Turín de 1523, atribuida a Juan Vespucio, copia del primer padrón real que registró el descubrimiento. Cf. Martinic (1999: 18).

31. Relación de Maximiliano Transilvano, op. cit. p. 276.

32. Como señala Lois (2008a: 280), durante el Renacimiento "el saber teórico y el saber práctico, más que discurrir por caminos separados, se entrelazaron ofreciendo mutuas condiciones de posibilidad para el desarrollo del otro (y, por tanto, uno no se puede entender sin el otro)". Roa de la Carrera (2002) se refiere al cuestionamiento de los conocimientos clásicos y medievales en su análisis de los planteamientos de Vespucio y destaca la comunicación entre teoría y práctica como condición para la producción de nuevos conocimientos cartográficos y requerimiento de la expansión imperial.

33. El capitán Francisco de Hoces, al mando de una de las naves de la expedición de García Jofré de Loaysa, había sido arrastrado por una tormenta desde la boca oriental del Estrecho hacia el sudeste, probablemente hasta los 56 (Martinic, 1999: 11).

34. 34 La categoría isla de tierra, ausente en las clasificaciones de las tierras emergidas del siglo XVI, es mencionada en la Capitulación y asiento que se tomó con Pedro Sancho de Hoz para efectuar descubrimientos en la Mar del Sur, del 24 de enero de 1539 (en Medina T. I, 1896). Si el criterio de la distinción entre continente e isla de tierra fuera la dimensión de la masa terrestre, la ausencia de precisiones sobre la extensión atribuida en cada caso no permite discriminar cuándo las tierras representadas corresponden a una u otra categoría.

35. 35 Una de las tres naves de la expedición antes de ingresar al estrecho habría sido arrastrada por un temporal hacia el sur sobre el Atlántico. Cf. Tanzi (1985: 47). 
36. 36 Mapas de Reinel (1522), Salviati (1525), Vespucio (1526), Ribero (1529), Santa Cruz (1542), Caboto (1544), Agnese (1545). Cf. Tanzi (1985: 30) y Martinic (1999: 65).

37. 37 En los mapas que representan el continente austral entre 1515 y 1540 se identifican dos regiones: Brasilia regio y Regio Patalis. El primer topónimo aparece en los globos de Schöner de 1515 y 1520 y se ubica al sur del estrecho que separa el continente austral del Nuevo Mundo, pudiendo ser un desplazamiento o confusión con el territorio de Brasil. El topónimo Patalis Regno derivaría de un pasaje de Plinio que refiere a un puerto en la India al sur del Ecuador; posteriormente Roger Bacon la ubica al sur del Trópico de Capricornio y Pierre d'Ailly mantiene la referencia en su Imago Mundi. Resulta probable que esta última obra haya sido la fuente de Schöner y Fineus. Cf. Van Duzer (2007: 193-222).

38. 38 Viajes a las costas de Nueva Guinea del portugués Jorge de Meneses (1526) y de los españoles Alvaro de Saavedra (1527-1528) y Ruy López de Velasco (1542-1545), expedición francesa de los hermanos Parmentier a Sumatra (1529-1530). Cf. Tanzi (1985).

39. 39 Las expediciones de F. García Jofré de Loaysa y J.S. Elcano (1525-1526), Simón de Alcazaba (1534-1535) y la Armada del Obispo de Plasencia (1539-1540) son descriptas en por J. Callander (1967: 110-201).

40. $40 \mathrm{Si}$ bien algunos autores ofrecen información sobre las negociaciones mantenidas en 1531 entre el Consejo de Indias y los banqueros Fugger, estrechamente ligados a Carlos V, para formalizar una jurisdicción desde el estrecho hasta el término de la gobernación de Pizarro, no se halló evidencia documental sobre la concreción del acuerdo. Nocetti y Mir (1997: 21) proponen la posibilidad de que los banqueros alemanes, que participaban del tráfico comercial portugués con las Indias Orientales desde principios del siglo XVI, pudieron desistir de la capitulación frente a las presiones de la Corona de Portugal interesada en desalentar un financiamiento que favorecía a sus competidores. Los Fugger venían financiando expediciones al servicio de Castilla, en concreto las de Magallanes y García de Loaysa.

41. 41 Gonzalo Fernández de Oviedo, Historia General y Natural de las Indias [1535-1557], en Biblioteca de Autores Españoles, Tomo CXVIII, vol. II, Madrid, Atlas, 1859, citado en Nocetti y Mir (1997).

42. 42 Medina, J.T, op. cit., Tomo VIII.

43. 43 Claudio Gay, Historia Física y Política de Chile. Documentos sobre la historia, la estadística y la geografía de Chile, Tomo Primero, París, 1846, p. 21, citado en Nocetti y Mir (1997: 28-30).

44. 44 Capitulación y asiento que se tomó con Pero Sancho de Hoz para efectuar descubrimientos en la Mar del Sur, en Medina T. I, 1896.

45. 45 Juan López de Velasco, el primer Cosmógrafo y Cronista Mayor del Consejo de Indias, elabora su descripción del Estrecho de Magallanes sobre el informe de Ladrillero y expone el juicio oficial sobre las condiciones de la ruta: "La navegación para Estrecho, por la mar del Sur y la del Norte, no se puede hacer sin mucho riesgo, sino en medio del verano, que como queda dicho es en los meses de diciembre y enero, porque en el otro tiempo son las tormentas muy continuas y muy bravas, de vientos noroestes y sudoestes que duran diez y doce días, y las nieves muy grandes, y fríos continuos con grande cerrazón y tenebrura, porque no hay más de seis horas de día, y aun en medio del verano las han hallado muy grandes y con mucho peligro los que han querido navegar el Estrecho, y así siempre la navegación de las costas de estas provincias es dificultosa y mal segura por estar en tanta altura; que aunque dentro y fuera del Estrecho no faltan muchos puertos buenos, son tan continuas las refriegas de los vientos $y$ tormentas que se puede mal aprovechar de ellos, y así todos los que han acometido a pasarle, y le han pasado, se han visto en grandes peligros y trabajos". Juan López de Velasco, Geografía y descripción universal de las Indias, 1575. Repositorio: University of California Libraries.

46. 46 Drake pudo haber usado el mapa del cartógrafo Fernando Vaz Dourado de 1570 que traza el estrecho en su orientación de "V" abierta (NESO-NO) y representa hacia el sur un conjunto insular y una costa que interrumpe a los $60^{\circ} \mathrm{LS}$ aproximadamente. 
47. 47 Según Wallis (1984: 121-150), estos mapas permanecieron bajo una estricta política del secreto hasta fines de la década del ochenta.

48. 48 Viaje al Estrecho de Magallanes por el Capitán Pedro Sarmiento de Gamboa en los años de 1579 y 1580 y noticia de la expedición que después hizo para poblarlo [Madrid, 1768], Buenos Aires, Eudeba, 2005.

49. 49 Las noticias del descubrimiento de Drake habrían llegado a España por distintas vías. Según Acosta, el Virrey de Nueva España había interrogado en 1579 al piloto portugués de la nave de Drake, Nuño da Silva, declarando éste "que el Estrecho hazia luego Isla, y se juntaban ambos mares". José de Acosta, Historia natural y moral de las Indias, 1590. Repositorio: Memoria Chilena Biblioteca Nacional Digital de Chile. Asimismo, el embajador español en Inglaterra, Bernardino de Mendoza, lo habría comunicado a la corte española en 1582 tras haber recibido información de una persona que había visto la carta confeccionada por Drake. Cf. Spate (2004).

50. 50 Los mapas de Gastaldi y los de inspiración gastaldina (G. Ruscelli, P. Forlani, F. Bertelli, G. F. Camoccio, entre otros) repiten tres topónimos: Tierra del Fuego, Tierra del Fuego Incognita y Terra Incognita.

51. José de Acosta, Historia natural y moral de las Indias, 1590. Repositorio: Memoria Chilena Biblioteca Nacional Digital de Chile.

\section{ABSTRACTS}

We approach the territorial construction of the southernmost tip of America, within the context of the Renaissance debates on the image of the world and the prospect of a southern ecumene. The analysis of cartographic, iconic and verbal records as part of the discourse narrative of the $16^{\text {th }}$ century maps, based on other documentary sources, aims at investigating the different ways of production of spatial knowledge at the outset of the process of discovery and exploration of the southern hemisphere. It is worthwhile showing the role that maps played in forging a template for the representation of the southern territories of South America as a frontier, the end of the known world and a passage to another possible world.

Se propone una aproximación a la construcción territorial del extremo meridional de América en el contexto de los debates renacentistas sobre la imagen del mundo y la posibilidad de un ecumene austral. El análisis de los registros cartográfico, icónico y verbal integrados en la trama discursiva de los mapas elaborados durante el siglo XVI, apoyado en otras fuentes documentales, se orienta a indagar sobre los modos de producción del conocimiento espacial en el inicio del proceso de descubrimiento y exploración del hemisferio sur. Interesa mostrar el papel que jugaron los mapas en la conformación de una matriz de representación de los territorios australes de Sudamérica como frontera, confín del mundo conocido y pasaje a otro mundo posible.

É proposta uma aproximação para a construção territorial do extremo meridional da América no contexto dos debates renascentistas sobre a imagem do mundo e a possibilidade de um ecúmeno austral. A análise dos registros cartográfica, icônica e verbal integradas na trama discursiva dos mapas elaborados durante o século XVI, apoiados em outras fontes documentais, está orientada a indagar sobre os modos de produção do conhecimento espacial no início do processo da descoberta e exploração do Hemisfério Sul. Interessa mostrar o papel que tiveram os mapas na 
conformação de uma matriz de representação dos territórios austrais da América do Sul como fronteira, limite do mundo conhecido e passagem a outro mundo possível.

Il est proposé une approche sur la construction territoriale de l'extrémité méridionale de l'Amérique dans le contexte des débats de la Renaissance sur l'image du monde et la possibilité d'un oïkoumène austral. L'analyse des registres cartographiques, iconiques et langagiers intégrés dans la trame discursive des cartes élaborées au cours du XVIème siècle, en s'appuyant sur d'autres sources documentaires, nous dirige vers la recherche d'autres modes de production de la connaissance spatiale au commencement de l'entreprise de découverte et d'exploration de l'hémisphère sud. Il est intéressant de montrer le rôle joué par les cartes dans la conformation d'une matrice de représentation des territoires australes d'Amérique du Sud en tant que frontière, confins du monde connu et passage à un autre monde possible.

\section{INDEX}

Chronological index: século XVI

Palabras claves: Terra Australis, Tierra del Fuego, imagen territorial, cartografía, siglo XVI Palavras-chave: Terra Australis, Tierra del Fuego, imagem territorial, cartografia, século XVI Geographical index: América do Sul, Terra do Fogo, Terra Australis Mots-clés: Terra Australis, Terre de Feu, image territoriale, cartographie du XVIème siècle Keywords: Terra Australis, Tierra del Fuego, territorial image, cartography, 16th century

\section{AUTHORS}

\section{LUIS IGNACIO DE LASA}

Licenciado en Geografía Profesor del Instituto de Cultura, Sociedad y Estado Universidad Nacional de Tierra del Fuego, Antártida e Islas del Atlántico Sur Fuegia Basquet 251. Ushuaia.Tierra del Fuego, Argentina

ldelasa@untdf.edu.ar

\section{MARÍA TERESA LUIZ}

Doctora en Historia Profesora del Instituto de Cultura, Sociedad y Estado Universidad Nacional de Tierra del Fuego, Antártida e Islas del Atlántico Sur Fuegia Basquet 251. Ushuaia.Tierra del Fuego, Argentina mtluiz@untdf.edu.ar 